\title{
Kinetic Studies of Atom Transfer Radical Polymerisations of Styrene and Chloromethylstyrene with Poly(3-hexyl thiophene) Macroinitiator
}

\author{
Nattawoot Rattanathamwat, ${ }^{1}$ Jatuphorn Wootthikanokkhan, ${ }^{1,2}$ Nonsee Nimitsiriwat, ${ }^{2,3}$ \\ Chanchana Thanachayanont, ${ }^{4}$ and Udom Asawapirom ${ }^{5}$ \\ ${ }^{1}$ Division of Materials Technology, School of Energy, Environment and Materials, King Mongkut's University of \\ Technology Thonburi (KMUTT), Bangkok 10140, Thailand \\ ${ }^{2}$ Nanotec-KMUTT Center of Excellence on Hybrid Nanomaterials for Alternative Energy (HyNAE), Bangkok 10140, Thailand \\ ${ }^{3}$ Pilot Plant Development and Training Institute, King Mongkut's University of Technology Thonburi, Bangkok 10140, Thailand \\ ${ }^{4}$ National Metal and Materials Technology Center (MTEC), Pathumthani 12120, Thailand \\ ${ }^{5}$ National Nanotechnology Center (NANOTEC), Pathumthani 12120, Thailand
}

Correspondence should be addressed to Jatuphorn Wootthikanokkhan; jatuphorn.woo@kmutt.ac.th

Received 15 October 2014; Revised 9 February 2015; Accepted 10 February 2015

Academic Editor: Doo-In Kim

Copyright (C) 2015 Nattawoot Rattanathamwat et al. This is an open access article distributed under the Creative Commons Attribution License, which permits unrestricted use, distribution, and reproduction in any medium, provided the original work is properly cited.

\begin{abstract}
Poly(3-hexyl thiophene)-b-poly(styrene-co-chloromethylstyrene) copolymers, to be used as a prepolymer for preparing donoracceptor block copolymers for organic solar cells, have been synthesised by reacting P3HT macroinitiators with styrene and chloromethylstyrene via three types of atom transfer radical polymerisation (ATRP) systems, which are (1) a normal ATRP, (2) activators generated by electron transfer (AGET), and (3) a simultaneous reverse and normal initiation (SR\&NI). The kinetics of these ATRP systems were studied as a function of monomers to the macroinitiator molar ratio. It was found that all of the three types of ATRP systems led to first order kinetics with respect to monomers. The highest rate constant (k) of $3.4 \times 10^{-3} \mathrm{~s}^{-1}$ was obtained from the SR\&NI ATRP system. The molecular weights of the product determined by the GPC were lower than were the theoretical values. The result was discussed in light of the chain transfer reaction to the poly(chloromethylstyrene) repeating units. Morphology of the synthesized block copolymers, examined by an atomic force microscopy (AFM), were also compared and discussed.
\end{abstract}

\section{Introduction}

Poly(3-hexyl thiophene) (P3HT) is a kind of semiconducting polymer that has been widely used in many electronic devices, including polymer solar cells [1]. In this case, P3HT serves as a donor material in an active layer of the cell, which is sandwiched between two different electrodes. The donor material is always used in combination with an electron acceptor material, such as fullerene $\left(\mathrm{C}_{60}\right)$ and/or a fullerene derivative $\left([6,6]\right.$-phenyl- $\mathrm{C}_{61}$-butyric acid methyl ester, $\mathrm{PCBM}$ ), to create an interpenetrating structure from the two different conducting materials. This structure, commonly called bulk heterojunction (BHJ), results in a relatively large interfacial area between the two phases. Consequently, more dissociations of an exciton (a tightly bound photo excited electron-hole pair) into free charges and a greater performance of the polymer solar cell can be expected [2].

However, power conversion efficiency (PCE) values of the $\mathrm{BHJ}$ polymer solar cells are still low compared to those of the conventional inorganic based solar cells and dye sensitised solar cells $[3,4]$. To enhance PCE of the polymer solar cell, various strategies can be used, including molecular design and synthesis of low band gap polymers to minimise photon loss [5]. In addition, morphology of the $\mathrm{BHJ}$ also plays a role. Since the diffusion length of the exciton is normally less than $10 \mathrm{~nm}$. In this regard, the performance of the polymer solar cell is extremely sensitive to the active layer morphology. For example, if the dimensions of the donor and the acceptor phases are larger than the exciton length, then 
it is likely that the photo-generated excitons are recombined before splitting into free charges. To suppress the exciton recombination, a nanoscale phase separated morphology of the donor/acceptor blend should be induced. The interfacial area between the donor and acceptor materials should also be as large as possible [6]. In addition, to minimise carrier losses, continuous pathways for both positive and negative charges towards the electrodes have to be ensured.

One possible strategy for inducing a nanostructured polymer solar cell is by using block copolymers as selforganising materials. Block copolymers self-assemble due to the incompatibility of the two blocks that are chemically linked to each other. The type of nanostructuring, taking place at the length scale of the two blocks, depends on their incompatibility, the chain length of the copolymer, and the volume fraction of the two blocks. Alternatively, a block copolymer might be used as a compatibilizer to control morphology of the donor/acceptor polymer blends [7]. By adding a suitable type and amount of a block copolymer into the polymer blend, a better interfacial adhesion and finer dispersed particles of the polymer blends can be expected.

In relation to our research, the block copolymer that is suitable for application in a photovoltaic device should contain a block with electron donating and another block with electron accepting moieties. This study focuses on the synthesis and photovoltaic performance of poly(3-hexyl thiophene)- $b$-fullerene grafted polystyrene (P3HT- $b$-PSFu) block copolymer. It was presumed that the PSFu block should be compatible with an electron acceptor phase $\left(\mathrm{C}_{60}\right.$ and/or $\mathrm{PCBM}$ ) in the active layer. The P3HT- $b$-PSFu molecule was prepared via a prepolymer, which is poly(3-hexyl thiophene)- $b$-poly(styrene-co-chloromethylstyrene) [P3HT$b$-P(S-co-CMS)]. This prepolymer, in turn, can be obtained from a controlled radical (co)polymerisation of styrene and chloromethylstyrene (CMS) with the P3HT macroinitator. It is worth mentioning that the use of CMS monomers containing chlorine atoms will enable the attachment of fullerene groups into the poly(chloromethylstyrene) (PCMS) repeating units.

Atom transfer radical polymerisation (ATRP) is considered to be one of the most robust and widely used controlled radical polymerisation techniques. Wang and Matyjaszewski first reported the ATRP technique in 1995 [8]. Since then, it has been widely used to prepare a variety of well-defined polymers with a PDI value $\left(M_{w} / M_{n}\right)$ of less than 1.5 . This technique can also lead to the formation of block copolymer architecture. In principle, this technique relies on the establishment of a dynamic equilibrium between the dormant species (end-capped radical chains) and the propagating radical chains. The polymerisation is initiated by the decomposition of an alkyl halide initiator, catalysed by the transition metal complex. In addition, a variety of modified ATRP techniques have recently been introduced. These include reverse ATRP, activators generated by electron transfer ATRP (AGET-ATRP) $[9,10]$, and simultaneous reverse and normal initiation ATRP (SR\&NI ATRP). It is noteworthy that rather than using low oxidation state metals that require special handling procedures and moisture free storage, AGET-ATRP and SR\&NI ATRP techniques employ a high oxidation state metal complex in combination with a radical initiator and/or a reducing agent, respectively. Consequently, an activator (low oxidation metal compound) is generated in situ and the reaction proceeds further in a similar fashion to that of the normal ATRP.

For a good phase separation and a high compatibilizing efficacy, it is important to ensure the preparation of a well-defined block copolymer. This can be achieved by controlling the molecular architecture (block length and block composition) of the donor/acceptor copolymer. In this regard, the kinetics of these ATRP systems are important and deserve consideration, taking into account the fact that monomer conversion, product yield, and molecular weight of the polymerised polymer strongly depend on the kinetics of the polymerisations. Khan et al. [11] studied the kinetics and product characteristics obtained from the polymerisation of MMA by different ATRP systems. It was found that modified ATRP employed a high oxidation state metal complex without any additives (so-called GAMA-ATRP) providing the best controllability and "living polymerisation" characteristics. Matyjaszewski et al. [12] studied the ATRP kinetics of styrene and found that the reaction kinetics exhibited first-order kinetics with respect to both the initiator and copper(I) halide concentration. The polymerisation kinetics were not simple inverse first-order with respect to the initial copper(II) halide concentration. This was ascribed to the persistent radical effect, which resulted in an increase in copper(II) concentration during the initial stages of the polymerisation. Arslan et al. [13] studied ATRP kinetics of styrene and found that the molecular weights of the product determined by GPC were higher than were the theoretical values. This was attributed to the slow deactivation rate of the catalytic system, which causes a rapid increase in the molecular weight at the beginning of polymerisation. Notably, when an initiator used for ATRP was a kind of polymeric molecule, the polymerisation kinetics could have been different from those of the system employing a low molecular weight initiator. For example, Lazzari et al. [14] prepared polyacrylonitrile-block polystyrene (PAN- $b$-PS) copolymers by ATRP, using bromine-terminated PAN macroinitiators. It was found that the first-order kinetic plots of styrene conversion showed a significant curvature. This indicated a progressive decrease in the concentration of active species during the copolymerisation. Results from ${ }^{1} \mathrm{H}$-NMR suggested the loss of the bromide end group, which was mainly ascribed to the elimination of $\mathrm{HBr}$.

In relation to this study, poly(3-hexyl thiophene)$b$-poly(styrene-co-chloromethylstyrene) [P3HT- $b$-P(S-coCMS)] were prepared from the ATRP of styrene and chloromethylstyrene (CMS) with the P3HT macroinitator. In the case of CMS, we hypothesised that the chlorine atoms in the CMS might be eliminated and transferred to a transition metal halide catalyst during the ATRP process. Consequently, the ATRP kinetics for CMS might be different from that of a normal ATRP system. To the best of our knowledge, an ATRP kinetics study of styrene and chloromethylstyrene with the P3HT macroinitator has not been reported in any open literature. The aim of this work was to investigate the kinetics of three different ATRP systems, namely normal 


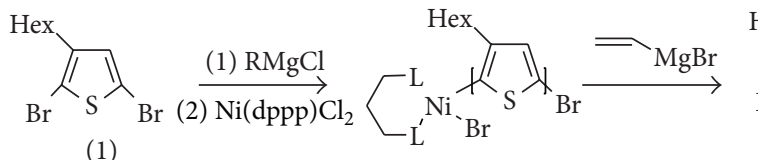

(1)

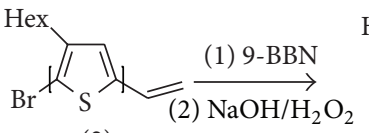

(2)

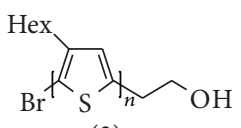

(3)<smiles>CC(Br)C(=O)Br</smiles><smiles>Cc1cc(CCOC(=O)C(C)Cc2ccc3c(CCl)ccc(CCl)c3c2)sc1C</smiles><smiles>C=Cc1ccc(CCl)cc1</smiles><smiles>CCc1cc(CCOC(=O)C(C)Br)sc1Br</smiles>

$(4)$

FIGURE 1: Schematic draw illustrating a synthetic route for preparing P3HT- $b$-P(S-co-CMS) via atom transfer radical polymerisation (ATRP).

ATRP, AGET-ATRP, and SR\&NI ATRP, as a function of the monomers/macroinitiator mole ratio. Morphology of the prepared block copolymer was also of our interest.

\section{Materials and Methods}

Styrene (99\% from Aldrich) and CMS (90\% from Fluka) were purified by passing them through an alumina column in order to remove any inhibitors. 2,5-dibromo-3-hexylthiophene (97\%), butyl magnesium chloride (2.0 M in diethyl ether), 1,3-bis(diphenylphosphino) propane dichloronickel (II), vinyl magnesium bromide (1.0 M in THF), 9-BBN, 2-bromopropionyl bromide (97\%), $\mathrm{Cu}(\mathrm{I}) \mathrm{Br}$ (98\%), $\mathrm{Cu}(\mathrm{II}) \mathrm{Br}$ (99.999\%), tin(II) 2-ethylhexanoate (95\%), and $\mathrm{N}, \mathrm{N}, \mathrm{N}^{\prime}, \mathrm{N}^{\prime \prime}, \mathrm{N}^{\prime \prime}$-pentamethyldiethylenetriamine (PMDETA) (99\%) were obtained from Aldrich and were used as received. Triethylamine (purum grade) was purchased from Fluka. Tetrahydrofuran (AR grade from Fisher) was refluxed over calcium hydride (reagent grade from Aldrich) for $24 \mathrm{~h}$ and was then distilled before use.

2.1. Preparation of the P3HT Macroinitator. The P3HT macroinitator was prepared using a multiple step synthetic route, in accordance with procedures described in the literature [15]. After that, the macroinitiator was further reacted with styrene and CMS monomers via three different ATRP systems (Figure 1). All reactions were carried out under nitrogen atmosphere using Schlenk line and cannula techniques.

2.1.1. Preparation of Vinyl-Terminated Poly(3-hexylthiophene). First, the vinyl-terminated $\mathrm{P} 3 \mathrm{HT}$ was prepared by adding 2,5dibromo-3-hexylthiophene (2.5 g, $7.5 \mathrm{mmoL})$ to a dry $250 \mathrm{~mL}$ Schlenk flask, which was emptied of oxygen by applying a vacuum, followed by nitrogen purging. This process was repeated for three cycles before keeping the solution under a nitrogen atmosphere. Next, anhydrous THF $(75 \mathrm{~mL})$ was transferred to the reaction flask via a cannula. A $2 \mathrm{M}$ solution of $\mathrm{BuMgCl}$ in diethyl ether $(7.5 \mathrm{~mL}, 15 \mathrm{mmoL})$ was added via a deoxygenated syringe and the reaction mixture was refluxed for $90 \mathrm{~min}$. After that, the solution was allowed to cool down to room temperature. $\mathrm{Ni}(\mathrm{dppp}) \mathrm{Cl}_{2}(0.15 \mathrm{~g}, 0.27 \mathrm{mmoL})$ was then added to the reaction mixture. The polymerization was allowed to proceed for $15 \mathrm{~min}$ at room temperature. Next, $1 \mathrm{M}$ solution of vinyl magnesium bromide in THF $(3 \mathrm{~mL}, 3 \mathrm{mmoL})$ was added via a syringe and the reaction mixture was stirred for $15 \mathrm{~min}$. After that, the reaction was terminated via precipitation into a large amount of methanol $(1 \mathrm{~L})$, where it was stirred for $1 \mathrm{~h}$. The precipitated product was filtered and purified by sequential soxhlet extractions with methanol, followed by hexane and dichloromethane, respectively. Finally, the product was dried in a vacuum oven at $45^{\circ} \mathrm{C}$ for $24 \mathrm{~h}$ or until it reached a constant weight. The chemical structure of the vinyl-terminated P3HT was confirmed using proton nuclear magnetic resonance $\left({ }^{1} \mathrm{H}\right.$ NMR) spectroscopy.

2.1.2. Preparation of Hydroxyl-Terminated Poly(3-hexylthiophene). Hydroxyethyl-terminated P3HT was prepared by further reacting the vinyl-terminated $\mathrm{P} 3 \mathrm{HT}$ with 9-BBN. Vinyl-terminated P3HT (2 g, $0.2 \mathrm{mmoL}, \mathrm{DP}_{n}$ determined by $\left.{ }^{1} \mathrm{H}-\mathrm{NMR}=32.61\right)$ was added to a dry $250 \mathrm{~mL}$ Schlenk flask. After five cycles of vacuum pumping and nitrogen purging, anhydrous THF $(100 \mathrm{~mL})$ was transferred into the reaction flask, under nitrogen atmosphere, via a double tipped needle. To this reaction mixture, a $0.5 \mathrm{M}$ solution of 9 - $\mathrm{BBN}(4 \mathrm{~mL}$, $2.0 \mathrm{mmoL}$ ) in anhydrous THF was added via a syringe. The reaction mixture was stirred for $24 \mathrm{~h}$ at $40^{\circ} \mathrm{C}$, and then a $6 \mathrm{M}$ solution of $\mathrm{NaOH}(2 \mathrm{~mL})$ was added to the reaction flask. The reaction mixture was stirred for another $15 \mathrm{~min}$ (at which point, the oil bath was removed). The reaction mixture was allowed to cool down to room temperature, which was followed by the addition of a $33 \%$ aqueous solution of hydrogen peroxide $(2 \mathrm{~mL})$, wherein the reaction was allowed to proceed for additional $24 \mathrm{~h}$ at $40^{\circ} \mathrm{C}$. The polymer was isolated by precipitation in a methanol-water mixture. The product was filtered and purified by a soxhlet extraction with 


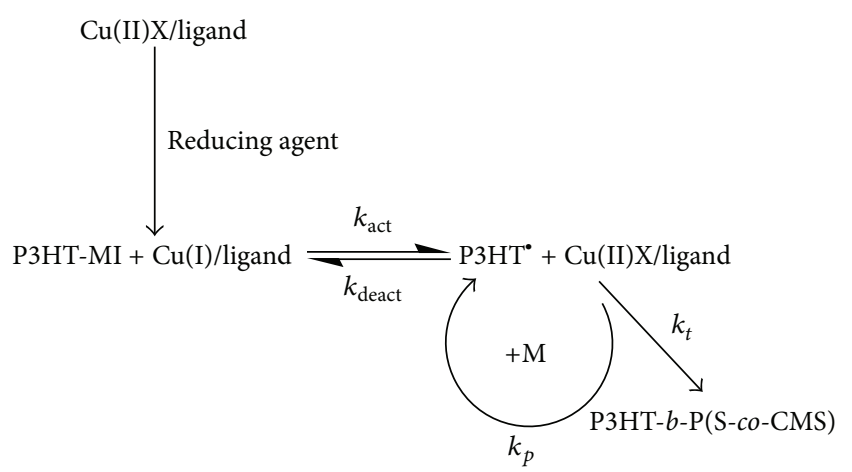

(a)

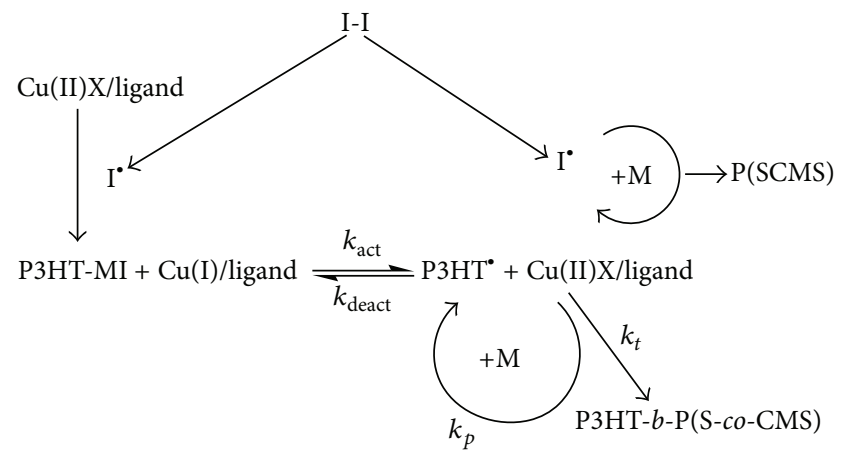

(b)

FIgURE 2: Mechanisms of (a) AGET-ATRP and (b) SR\&NI ATRP.

methanol. The chemical structure of hydroxyl-terminated P3HT was confirmed by ${ }^{1} \mathrm{H}$ NMR analysis.

2.1.3. Preparation of the P3HT Macroinitator. Finally, the P3HT macroinitator was prepared by dissolving the hydroxyl-terminated P3HT $(1 \mathrm{~g}, 0.1 \mathrm{mmoL})$ in anhydrous THF $(100 \mathrm{~mL})$ under nitrogen atmosphere. The reaction mixture was stirred for $15 \mathrm{~min}$ at $40^{\circ} \mathrm{C}$, followed by the addition of triethylamine $(9 \mathrm{~mL}, 66 \mathrm{mmoL})$ and a drop-wise addition of 2-bromopropionyl bromide $(7.5 \mathrm{~mL}, 60 \mathrm{mmoL})$. The reaction mixture was stirred for $24 \mathrm{~h}$ at $40^{\circ} \mathrm{C}$. The resulting P3HT macroinitator was precipitated in methanol and refluxed over methanol, followed by drying under vacuum at $45^{\circ} \mathrm{C}$ for $24 \mathrm{~h}$. The chemical structure and molecular weight of the synthesised polymer were characterised by ${ }^{1} \mathrm{H}$ NMR spectroscopy. Number average molecular weight $\left(M_{n}\right)$ and weight average molecular weight $\left(M_{w}\right)$ of the polymer, as determined by GPC, were $7,100 \mathrm{~g} / \mathrm{moL}$ and $9,122 \mathrm{~g} / \mathrm{moL}$, respectively.

2.2. Atom Transfer Radical Polymerisation. The P3HT macroinitator $(1 \mathrm{~g}, 0.1 \mathrm{mmoL})$ and $\mathrm{CuBr}(0.14 \mathrm{~g}, 0.1 \mathrm{mmoL})$ were added to a dry Schlenk flask. After applying a vacuum, followed by nitrogen purging for five cycles, the reaction mixture was immersed in a thermostat oil bath at $100^{\circ} \mathrm{C}$. Then, a solution of PMDETA $(0.02 \mathrm{~mL}, 0.1 \mathrm{mmoL})$, styrene $(1.70 \mathrm{~mL}$, $15 \mathrm{mmoL})$ and CMS (2.13 mL, $15 \mathrm{mmoL})$ in $5 \mathrm{~mL}$ of dried THF was transferred into the reaction flask, using a deoxygenated syringe. The polymerisation was allowed to proceed at $100^{\circ} \mathrm{C}$ for a given time, ranging from 60 to $240 \mathrm{~min}$. After that, the polymerisation was terminated by precipitation into a large amount of methanol. The residual catalyst was removed from the precipitate product by passing the polymer solution through an alumina column. The product was then washed with methanol. Notably, the product was also extracted with ether, DMSO, and acetone (which are selective solvents for this system) in order to ensure that the synthesised copolymer was free from any possible homopolymer contaminants. Finally, the product was dried in a vacuum oven at $45^{\circ} \mathrm{C}$ for $24 \mathrm{~h}$, or until it reached a constant weight.

To determine the monomer conversion and theoretical molecular weight of the polymerised product, the sample was periodically withdrawn from the reaction mixture with a degassed syringe. Monomer conversion was evaluated from the ${ }^{1} \mathrm{H}-\mathrm{NMR}$ spectrum of the crude product. In addition, theoretical values of degree of polymerisation $\left(\mathrm{DP}_{n}\right)$ of the polymerised product with respect to styrene and CMS monomers can also be determined by using

$$
\mathrm{DP}_{n(i)}=\frac{\left[M_{i}\right]_{0}}{[\text { initiator }]_{0}} \times \text { conversion. }
$$

2.3. AGET-ATRP and SR\&NI ATRP. By using $\mathrm{CuBr}_{2}$ as a replacement for the $\mathrm{CuBr}$ transition metal catalyst, the AGET-ATRP, and SR\&NI ATRP were carried out in similar procedures. In these cases, $\mathrm{Sn}(\mathrm{EH})_{2}$ and AIBN were used as an activator and initiator, respectively (Figure 2). More specific details concerning the polymerisation recipe for each ATRP system are summarised in Table 1.

2.4. Preparation of Donor-Acceptor Block Copolymers. Finally, a kind of electron donor-acceptor block copolymers, namely poly(3-hexyl thiophene)- $b$-fullerene grafted polystyrene (P3HT- $b$-PSFu), to be used as a compatibilizer in bulk heterojunction polymer solar cells were prepared via a fullerenation. The fullerene $\left(\mathrm{C}_{60}\right)$ groups were attached onto the P3HT- $b$-P(S-co-CMS) molecules via an Atom transfer radical addition (ATRA). Typical experimental procedures are as followed. To a $250 \mathrm{~mL}$ three-necked flask, $0.1 \mathrm{~g}$ of the P3HT- $b-\mathrm{P}(\mathrm{S}-\mathrm{co}-\mathrm{CMS})$ was mixed with the $\mathrm{C}_{60}$ $(0.013 \mathrm{~g})$, bipyridine $(0.03 \mathrm{~g})$, and dichlorobenzene $(15 \mathrm{~mL})$. The solution was purged with nitrogen gas for $15 \mathrm{~min}$ and then sealed with paraffin film and kept for further ATRA reactions. Next, $\mathrm{Cu}(0.013 \mathrm{~g})$ and $\mathrm{CuBr}(0.0086 \mathrm{~g})$ were added to a $250 \mathrm{~mL}$ three necked round bottom flask. The flask was closed with a rubber septum and sealed before undergoing vacuum and nitrogen purge for 5 cycles. Then, the above prepared polymer solution was introduced into the reaction flask by injection with a syringe through the rubber septum. The mixture was then refluxed at $100^{\circ} \mathrm{C}$ in an oil bath for $24 \mathrm{~h}$. After cooling to room temperature, content in the reaction flask was filtrated and precipitated with excess amounts of methanol. The crude precipitated product was re-dissolved in THF and the mixture was passed through 
TABLE 1: Recipes for carrying out ATRP for styrene and chloromethylstyrene with the use of P3HT macroinitiator.

\begin{tabular}{lccccc}
\hline Polymerization methods & & \multicolumn{3}{c}{ Molar compositions of the chemicals } \\
& {$[\mathrm{Cu}(\mathrm{I}) \mathrm{Br}]$} & {$\left[\mathrm{Cu}(\mathrm{II}) \mathrm{Br}_{2}\right]$} & {$[\mathrm{PMDETA}]$} & {$[\mathrm{AIBN}]$} & - \\
\hline AGET ATRP & - & 1 & 1 & 0.2 & - \\
SR\&NI ATRP & - & 1 & 1 & - \\
Normal ATRP & 1 & - & 1 & - \\
\hline
\end{tabular}

Styrene $=1.7 \mathrm{~mL}$, chloromethylstyrene $=2.13 \mathrm{~mL}, \mathrm{P} 3 \mathrm{HT}=1 \mathrm{~g}, \mathrm{Cu}(\mathrm{II}) \mathrm{Br}_{2}=0.223 \mathrm{~g}, \mathrm{PMDEA}=0.02 \mathrm{~mL}$,

(i) $\mathrm{Sn}(\mathrm{EH})_{2}=0.00648 \mathrm{~mL}$ for the AGET-ATRP system.

(ii) $\mathrm{AIBN}=0.003 \mathrm{~mL}$ for the SR\&NI-ATRP system.

(iii) $\mathrm{Cu}(\mathrm{I}) \mathrm{Br}=0.14 \mathrm{~mL}$ for the normal ATRP system.

an alumina column in order to remove the copper catalyst and then and precipitated into a large amount of methanol. The crude precipitated product was re-dissolved in THF, and then precipitated in methanol again. Hexane, which is a selective solvent for $\mathrm{C}_{60}$ and a nonsolvent for the polymer, was used to remove any residual $\mathrm{C}_{60}$ from the product. UV-visible spectroscopy was used to examine the presence of a characteristic absorption peak of free $\mathrm{C}_{60}$ in the leached solvent. The washing process was carried out until the aforementioned UV-visible peak (wavelength $335 \mathrm{~nm}$ ) was absent. Finally, the purified product was dried in a vacuum oven at $45^{\circ} \mathrm{C}$ until reaching a constant weight $(\sim 24 \mathrm{~h})$. The donor-acceptor block polymer was characterized by UV/Visible spectroscopy and thermal gravimetric analysis (TGA). More details concerning the characterizations can be found elsewhere [16].

2.5. Characterisations. The chemical structure of the synthesised polymer was verified using the ${ }^{1} \mathrm{H}$-NMR technique. The sample for the ${ }^{1} \mathrm{H}$-NMR experiments was prepared by dissolving $5 \mathrm{mg}$ of the polymer in $5 \mathrm{~mL}$ of deuterated chloroform $\left(\mathrm{CDCl}_{3}\right)$. The NMR experiment was carried out with a Bruker instrument $(500 \mathrm{MHz}$, ADVANCE DPX 300 model) using tetramethylsilane (TMS) as an external reference at $20^{\circ} \mathrm{C}$.

The molecular weight of the purified products was determined by using a gel permeation chromatography (GPC) technique, with the use of a Water (Breeze2 HPLC System) instrument equipped with an RI detector. THF was used as an eluent and $100 \mu \mathrm{L}$ of the sample solution $(3 \mathrm{mg} / \mathrm{mL}$ in THF) was prepared and filtered with a nylon 66 membrane before injection. GPC was operated at a flow rate of $1.0 \mathrm{~mL} / \mathrm{min}$. The obtained GPC chromatogram was then translated into a molecular weight distribution (MWD) curve via the use of a polystyrene narrow molecular weight calibration curve. The average molecular weight and polydispersity index were determined using standard equations.

Thermal behaviour of the synthesised block copolymer was characterised by thermal gravimetric analysis (TGA), using a Mettler Toledo (TGA/SDTA 851) instrument. The sample $(10 \mathrm{mg})$ was used and then heated over temperatures ranging from 25 to $800^{\circ} \mathrm{C}$, at a heating rate of $10^{\circ} \mathrm{C} / \mathrm{min}$, under nitrogen atmosphere.

Morphology and surface topographical features of the prepared block copolymers were examined by Atomic Force Microscopy (AFM; Seiko Instruments SPA-400). Briefly,

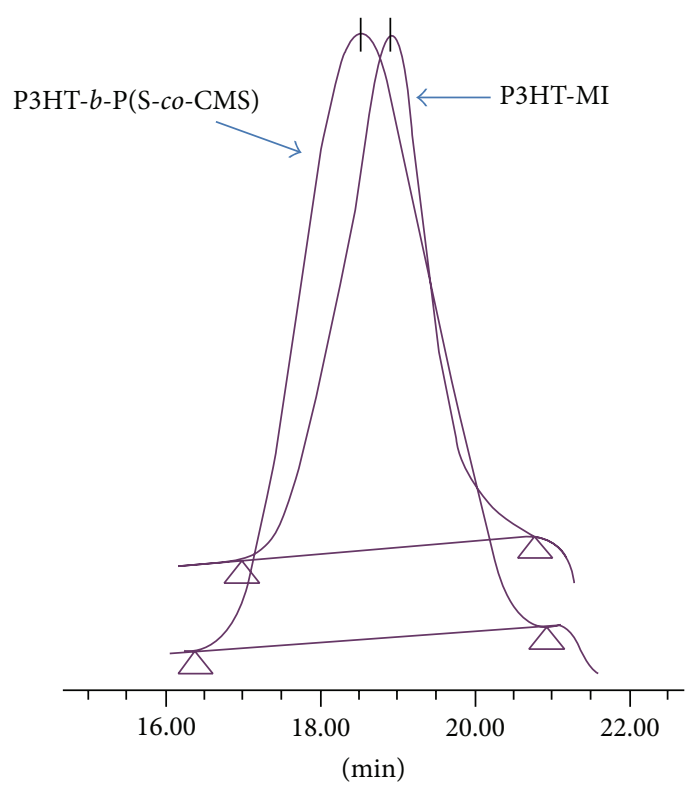

FIGURE 3: Overlaid GPC chromatograms of the P3HT macroinitiator and that of the product obtained from ATRP.

a solution of the sample was spin coated onto a silicon $(\mathrm{Si})$ substrate, at room temperature. Solvent was evaporated by drying at $50^{\circ} \mathrm{C}$ under reducing pressure in a vacuum oven $\left(10^{-2}\right.$ mbar). The samples than underwent AFM analysis and the corresponding images were examined by using a phase image tapping mode and a topographic mode.

\section{Results and Discussion}

The molecular weight of P3HT- $b$-P(S-co-CMS) was determined using the GPC technique, as shown in Figure 3. The GPC peak of the macroinitiator shifted to a shorter retention time, indicating that the molecular weight of the polymer product increased. By using a calibration curve, $M_{n}$ of the P3HT macroinitator and the corresponding product were 7,100 and $9,300 \mathrm{~g} / \mathrm{mol}$, respectively. This indicates that further reactions with styrene and CMS extended the chain length of the macroinitiator.

The chain extension of the P3HT macroinitator was further confirmed by the ${ }^{1} \mathrm{H}$-NMR. Figure 4 shows the ${ }^{1} \mathrm{H}$ NMR spectrum of the $\mathrm{P} 3 \mathrm{HT}$ macroinitator. Characteristic 


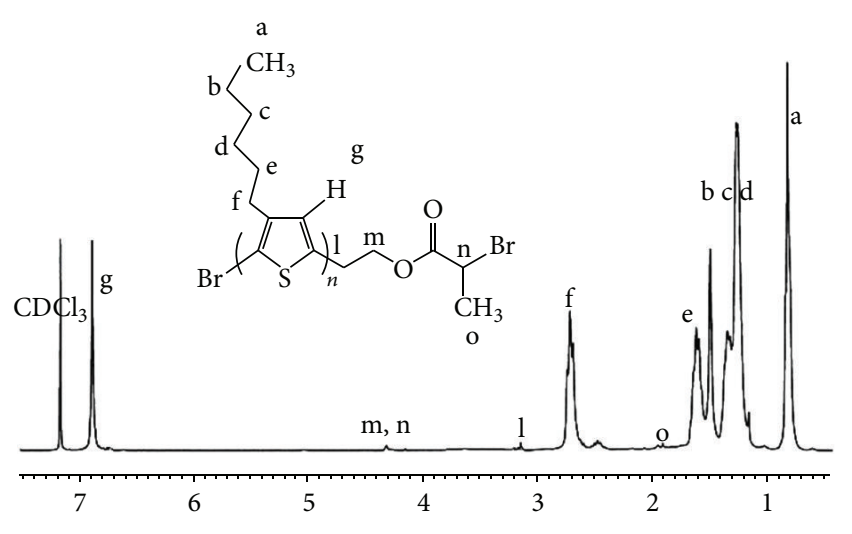

Figure 4: ${ }^{1} \mathrm{H}-\mathrm{NMR}$ spectrum of the P3HT macroinitiator.

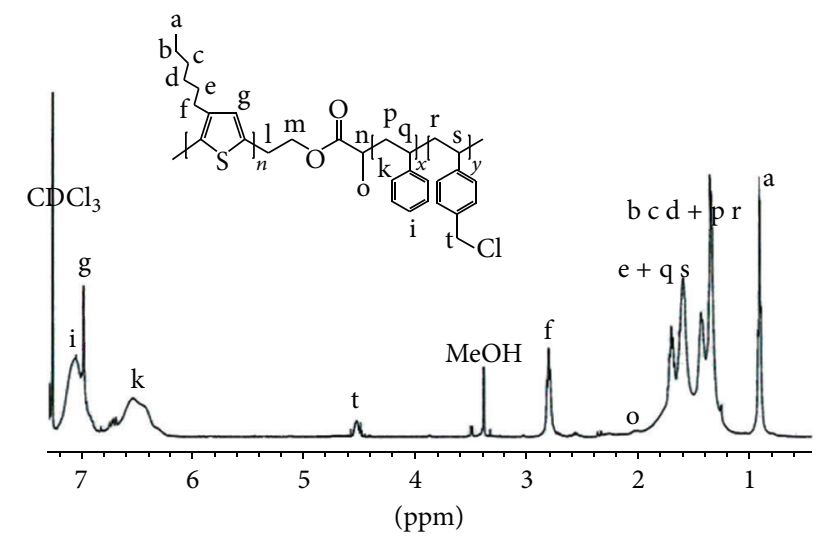

FIgURE 5: ${ }^{1} \mathrm{H}-\mathrm{NMR}$ spectrum of the P3HT- $b$-P(S-co-CMS).

monomer peaks at 1.9, 3.2 and 4.3 ppm that represent the protons in the bromopropionate end groups of the macroinitiator can be seen. The peak at $6.8 \mathrm{ppm}$ can be ascribed to the aromatic protons of the $\mathrm{P} 3 \mathrm{HT}$ main chains. After carrying out the ATRP, the peaks at 7.0 and 7.3 ppm emerged (Figure 5). These could be attributed to the aromatic protons in the repeating units of $\mathrm{P}(\mathrm{CMS})$ and $\mathrm{PS}$, respectively. On the other hand, the above spectrum lacks peaks at 5.2 and $5.7 \mathrm{ppm}$ of the olefinic proton, indicating that there are no residual monomers in the purified product. The peak at 4.3, representing the protons in the bromopropionate end group of the macroinitiator, also disappears, whereas the peak at $4.6 \mathrm{ppm}$, belonging to the methylene protons adjacent to the chlorine atom of the $\mathrm{P}(\mathrm{CMS})$ repeating units, appears. The above spectral changes are sufficient to confirm that the P3HT- $b$-P(S-co-CMS) was obtained. Similar spectral changes were observed from the ${ }^{1} \mathrm{H}-\mathrm{NMR}$ spectrum of $\mathrm{P} 3 \mathrm{HT}-b$-P(Sco-CMS), prepared by using different ATRP conditions. In addition, by using the characteristic NMR peaks representing each repeating unit, compositions of the copolymers can be determined. These results are summarised in Table 2.

It is worth noting that a majority of the $\mathrm{P}(\mathrm{S}-\mathrm{co}$ CMS) block contains PS repeating units, regardless of the monomer/macroinitiator mole ratio. The composition also changed with the polymerisation time, that is, the longer

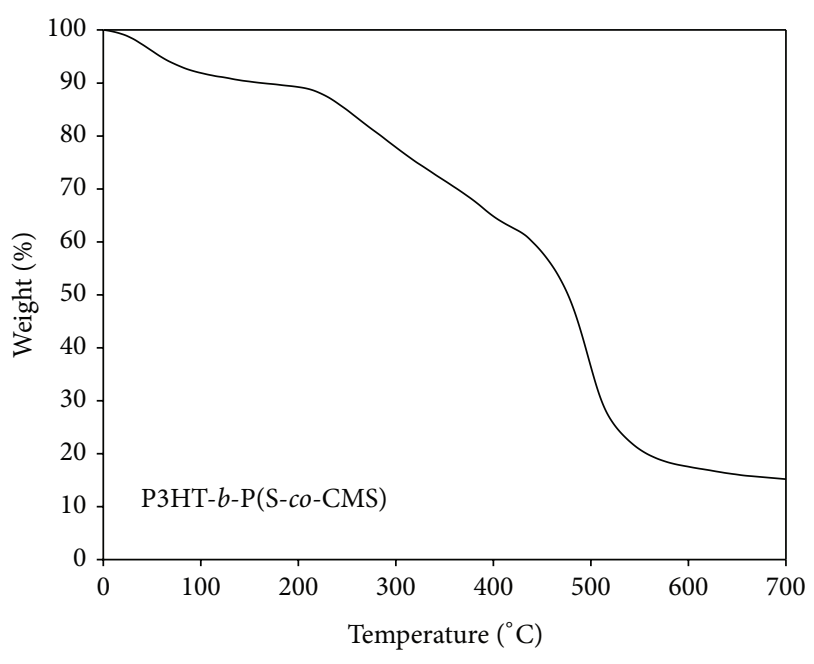

FIGURE 6: TGA thermogram of the P3HT- $b$-P(S-co-CMS).

the time, the greater the $\mathrm{P}(\mathrm{CMS})$ content. This could be ascribed to the different monomer reactivity ratios and to a composition drift effect [17]. In addition, our earlier work concerning a synthesis of PPV-g-P(S-co-CMS) via iniferter polymerisation [18] also revealed that the reactivity ratios of CMS and styrene, determined using the Fineman-Ross equation [19], are 0.11 and 0.51 , respectively.

In addition, side reactions during ATRP might also be possible. Our control experiments involving free radical copolymerisations of styrene and CMS via the use of either AIBN or iniferter polymerisations revealed that the $\mathrm{P}(\mathrm{CMS})$ composition in the $\mathrm{P}(\mathrm{S}-\mathrm{co}-\mathrm{CMS})$ chains are $47.57 \%$ and $43.82 \%$, respectively. These values are significantly higher than those obtained from the ATRP when the same monomer/feed mole ratio was used (50/50). This discrepancy implies that some side reactions might occur during the ATRP. This includes a chain transfer reaction to the chlorine atoms in the $\mathrm{P}$ (CMS) units of the copolymer, leading to some changes and/or deviations in the copolymer composition.

Figure 6 shows a TGA thermogram of the product obtained from copolymerisation of styrene and chloromethylstyrene at $100^{\circ} \mathrm{C}$ for $180 \mathrm{~min}$ via the ATRP technique. A three-step transition can be observed. The first transition occurred over a temperature range of between 50 and $150^{\circ} \mathrm{C}$, involving approximately a $10 \%$ weight loss, which can be ascribed to the evaporation of absorbed water on the sample's surface. Next, the second weight loss (27 wt\%) occurred over a temperature range of $220-390^{\circ} \mathrm{C}$. This could be related to the decomposition of $\mathrm{P}(\mathrm{S}-\mathrm{co}-\mathrm{CMS})$ units $[20,21]$. Finally, the third transition, which accounted for $48 \%$ of the weight loss, represents the decomposition of $\mathrm{P} 3 \mathrm{HT}$ [22]. Above $700^{\circ} \mathrm{C}$, no further weight loss was observed and the remaining weight is attributed to residual solids.

3.1. ATRP Kinetics. Figure 7 shows that the monomer conversion increases with the polymerisation time and tends to reach a plateau after $120 \mathrm{~min}$. This can be ascribed to the fact that the ATRP is a type of controlled radical polymerisation. 
TABLE 2: Effects of monomer:macroinitiator mole ratios and polymerization times on monomers conversions, molecular weights, and compositions of the P3HT- $b$-P(S-co-CMS) copolymers obtained from ATRP of styrene and chloromethylstyrene.

\begin{tabular}{|c|c|c|c|c|c|c|c|}
\hline \multicolumn{2}{|c|}{ Conditions } & \multirow{2}{*}{$\begin{array}{c}\text { Monomers } \\
\text { conversion (\%) }\end{array}$} & \multicolumn{3}{|c|}{ P3HT- $b$-P(S-co-CMS) compositions } & \multicolumn{2}{|c|}{ Molecular weight analysis } \\
\hline $\begin{array}{l}\text { Polymerization } \\
\text { time (min) }\end{array}$ & $\begin{array}{c}\text { Monomers/P3HT } \\
\text { mole ratios }\end{array}$ & & $\begin{array}{l}\mathrm{P}(\mathrm{SCMS}) \text { block } \\
(\% \mathrm{~mol})\end{array}$ & PS (\% mol) & $\begin{array}{l}\mathrm{P}(\mathrm{CMS}) \\
(\% \mathrm{~mol})\end{array}$ & $M_{n}(\mathrm{~g} / \mathrm{mol})$ & PDI \\
\hline \multirow{2}{*}{60} & $300: 1$ & 25.40 & 14.16 & 72.73 & 27.27 & 9,774 & 1.09 \\
\hline & $200: 1$ & 19.63 & 4.84 & 77.06 & 22.94 & 8,249 & 1.07 \\
\hline \multirow{2}{*}{90} & $300: 1$ & 30.27 & 16.32 & 73.85 & 26.15 & 9,973 & 1.09 \\
\hline & $200: 1$ & 26.18 & 8.41 & 73.85 & 26.15 & 9,321 & 1.05 \\
\hline \multirow{2}{*}{120} & $300: 1$ & 36.04 & 18.37 & 74.67 & 25.33 & 11,698 & 1.06 \\
\hline & $200: 1$ & 29.99 & 12.79 & 69.70 & 30.30 & 10,112 & 1.05 \\
\hline \multirow{2}{*}{180} & $300: 1$ & 43.08 & 20.51 & 69.70 & 30.30 & 13,488 & 1.13 \\
\hline & $200: 1$ & 35.51 & 16.53 & 70.97 & 29.03 & 11,190 & 1.08 \\
\hline \multirow{2}{*}{240} & $300: 1$ & 50.14 & 28.57 & 65.61 & 34.39 & 15,934 & 1.12 \\
\hline & $200: 1$ & 38.55 & 18.57 & 68.21 & 31.79 & 12,079 & 1.11 \\
\hline
\end{tabular}

Styrene/CMS mole ratio $=50 / 50$.

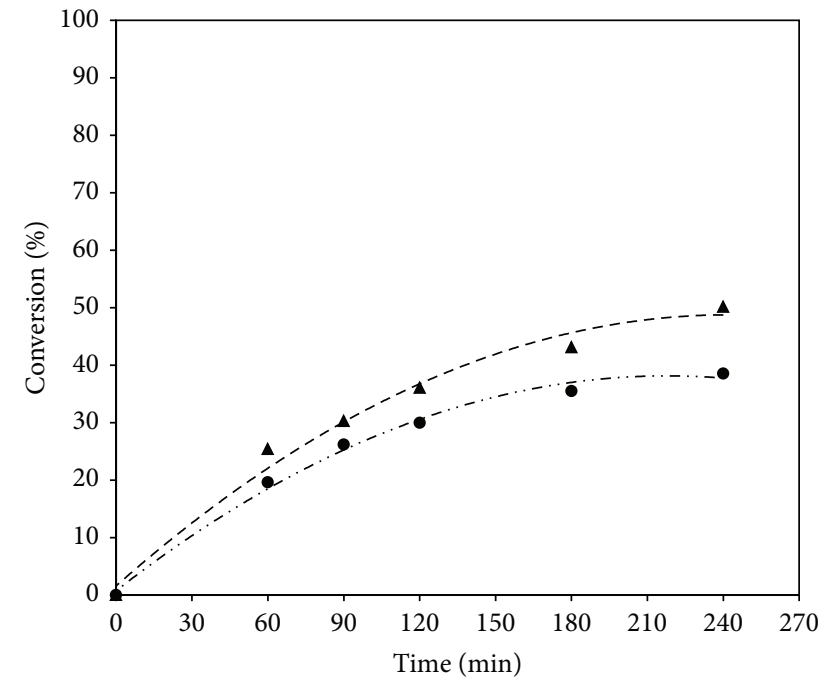

\ Normal ATRP $[\mathrm{M}]:[\mathrm{P} 3 \mathrm{HT}-\mathrm{MI}]=300: 1$

- Normal ATRP $[\mathrm{M}]:[\mathrm{P} 3 \mathrm{HT}-\mathrm{MI}]=200: 1$

FIGURE 7: Relationships between monomer conversion and reaction time during ATRP of styrene and CMS at $100^{\circ} \mathrm{C}$.

The propagating chains are reversibly reacted with bromine atoms, serving as a capping agent. Consequently, the longer the reaction times, the higher the chances for monomers to react with the propagating chains. After a prolonged polymerisation time beyond $120 \mathrm{~min}$, the conversion gradually increased with time, possibly due to changes in monomer composition and depletion of the macroinitiator.

Figure 7 also shows that by increasing the monomers/ macroinitiator mole ratio from $200: 1$ to $300: 1$, the monomer conversion and percentage mole of the $\mathrm{P}$ (S-co-CMS) block increases, regardless of the polymerisation techniques. This is due to the fact that the higher the mole ratio, the greater the polymerisation rate. The above statement is supported by the results from the kinetic plot of $\operatorname{Ln}\left[M_{0}\right] /[M]$ versus time

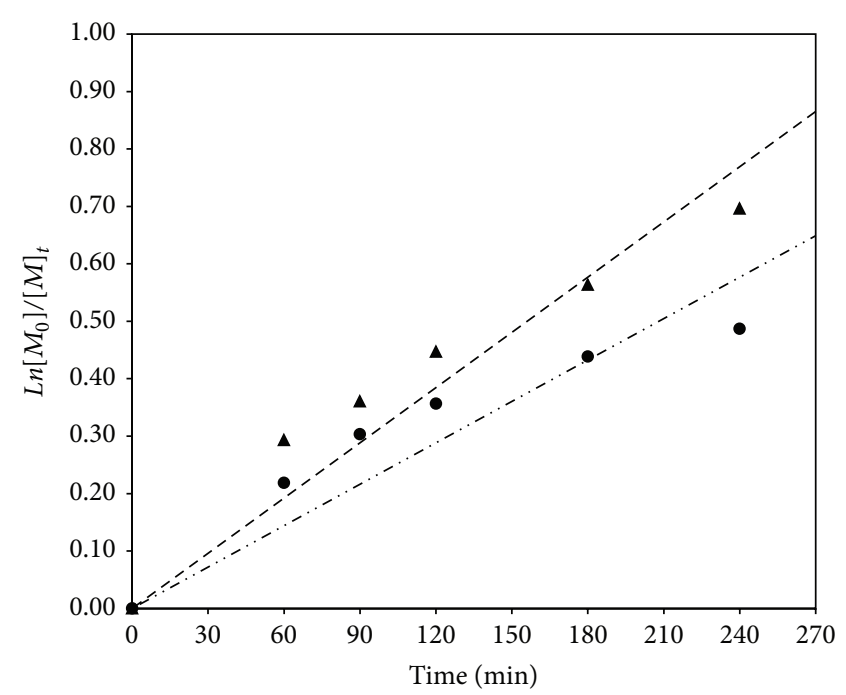

\ Normal ATRP $[\mathrm{M}]:[$ P3HT-MI $]=300: 1$

- Normal ATRP $[\mathrm{M}]:[\mathrm{P} 3 \mathrm{HT}-\mathrm{MI}]=200: 1$

FIgURE 8: Kinetic plots of $\operatorname{Ln}\left[M_{0}\right] /[M]$ versus time for ATRP of styrene and CMS with the P3HT macroinitator (using different monomers/macroinitiator mole ratios).

for the ATRP of styrene and CMS (Figure 8), which led to the calculated rate constants of $1.9 \times 10^{-3}$ and $2.7 \times 10^{-3} \mathrm{~s}^{-1}$ for the ATRP using the mole ratios of $200: 1$ and $300: 1$, respectively.

Figure 9 shows the dependence of the molecular weight and polydispersity index (PDI) on monomer conversion for the ATRP of styrene and CMS with the P3HT macroinitator. The PDI values of the polymerised products ranged from between 1.05 and 1.13. These values are considerably lower when compared to those obtained from normal free radical polymerisations and/or other controlled radical polymerisation techniques, such as iniferter polymerisation [9]. For example, our control experiments concerning free radical copolymerisation of the styrene and CMS via the use of AIBN 
TABLE 3: Monomers conversions, molecular weights, and compositions of the P3HT- $b$-P(S-co-CMS) copolymers obtained from various ATRP systems.

\begin{tabular}{|c|c|c|c|c|c|c|c|}
\hline \multicolumn{2}{|c|}{ Conditions } & \multirow{2}{*}{$\begin{array}{c}\text { Monomers } \\
\text { conversion (\%) }\end{array}$} & \multicolumn{3}{|c|}{ P3HT- $b$-P(S-co-CMS) compositions } & \multicolumn{2}{|c|}{ Molecular weight analysis } \\
\hline $\begin{array}{l}\text { Polymerization } \\
\text { time (min) }\end{array}$ & ATRP methods & & $\begin{array}{l}\mathrm{P}(\mathrm{SCMS}) \text { block } \\
(\% \mathrm{~mol})\end{array}$ & PS (\% mol) & $\begin{array}{l}\mathrm{P}(\mathrm{CMS}) \\
(\% \mathrm{~mol})\end{array}$ & $M_{n}(\mathrm{~g} / \mathrm{mol})$ & PDI \\
\hline \multirow{3}{*}{60} & AGET ATRP & 35.75 & 22.74 & 75.73 & 24.27 & 9,194 & 1.09 \\
\hline & SR\&NI ATRP & 16.78 & 16.45 & 86.11 & 13.89 & 9,671 & 1.07 \\
\hline & Normal ATRP & 25.40 & 14.16 & 72.73 & 27.27 & 9,774 & 1.09 \\
\hline \multirow{3}{*}{90} & AGET ATRP & 41.34 & 24.78 & 75.61 & 24.39 & 10,314 & 1.05 \\
\hline & SR\&NI ATRP & 25.12 & 18.51 & 81.48 & 18.52 & 10,067 & 1.06 \\
\hline & Normal ATRP & 30.27 & 16.32 & 73.85 & 26.15 & 9,973 & 1.05 \\
\hline \multirow{3}{*}{120} & AGET ATRP & 45.03 & 25.54 & 72.22 & 27.78 & 11,541 & 1.13 \\
\hline & SR\&NI ATRP & 38.71 & 20.25 & 73.33 & 26.67 & 11,572 & 1.08 \\
\hline & Normal ATRP & 36.04 & 18.37 & 74.67 & 25.33 & 11,698 & 1.12 \\
\hline \multirow{3}{*}{180} & AGET ATRP & 50.71 & 25.60 & 70.09 & 29.91 & 12,592 & 1.11 \\
\hline & SR\&NI ATRP & 45.65 & 23.78 & 68.35 & 31.65 & 13,646 & 1.05 \\
\hline & Normal ATRP & 43.08 & 20.51 & 69.70 & 30.30 & 13,488 & 1.21 \\
\hline 180 & Iniferter & $\mathrm{n} / \mathrm{a}$ & $\mathrm{n} / \mathrm{a}$ & 56.18 & 43.82 & 8,504 & 1.84 \\
\hline 180 & $\begin{array}{c}\text { Normal FRP } \\
\text { with AIBN }\end{array}$ & $\mathrm{n} / \mathrm{a}$ & $\mathrm{n} / \mathrm{a}$ & 52.43 & 47.57 & 9,069 & 2.28 \\
\hline \multirow{3}{*}{240} & AGET ATRP & 54.82 & 29.58 & 64.29 & 35.71 & 16,989 & 1.12 \\
\hline & SR\&NI ATRP & 55.54 & 31.11 & 60.67 & 39.33 & 16,404 & 1.09 \\
\hline & Normal ATRP & 50.14 & 28.57 & 65.61 & 34.39 & 15,934 & 1.23 \\
\hline
\end{tabular}

Monomers/P3HT macroinitiator mole ratio = 300/1; styrene/CMS mole ratio $=50 / 50$.

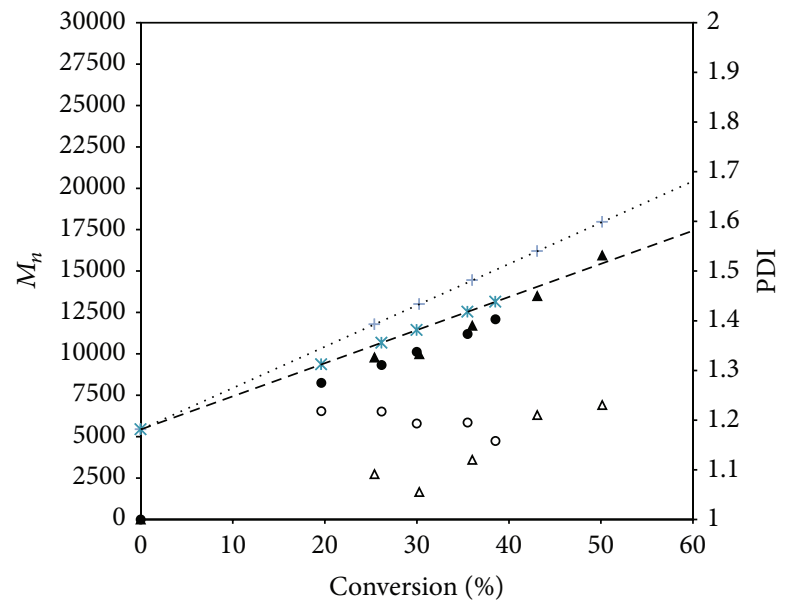

$\Delta$ Normal ATRP $[\mathrm{M}]:[\mathrm{P} 3 \mathrm{HT}-\mathrm{MI}]=300: 1$

- Normal ATRP $[\mathrm{M}]:[\mathrm{P} 3 \mathrm{HT}-\mathrm{MI}]=200: 1$

$+M_{n}($ th) $300: 1$

* $M_{n}$ (th) $200: 1$

$\Delta$ (PDI) normal ATRP [M] : [P3HT-MI] $=300: 1$

FIGURE 9: Dependence of molecular weight and polydispersity index on monomer conversion for the ATRP of styrene and CMS with the P3HT macroinitator (using different monomers/macroinitiator mole ratios).

and/or the use of iniferter polymerisation revealed that the obtained PDI values of the products lies between 2.28 and 1.84 , respectively (Table 3 ).
Notably, in all cases, the actual $M_{n}$ determined from the GPC technique is lower than that of the theoretical $M_{n}$, regardless of the monomers/macroinitiator mole ratios. In particular, the polymers prepared using the higher mole ratio $(300: 1)$ showed this trend at the highest level, that is, the higher the mole ratio, the greater the discrepancy. This result implies that nonnegligible chain transfer reactions occurred during the polymerisation [11].

3.2. Comparisons of Various ATRP Systems. Figure 10 shows the relationships between monomer conversion and reaction time during the copolymerisation of styrene and CMS using normal ATRP, AGET-ATRP and SR\&NI ATRP, respectively. The monomer conversion linearly increases with time before reaching a plateau. This can be explained in a similar fashion to the above results, as shown in Figure 8. It is worth nothing that at a shorter polymerisation time, the monomer conversion obtained from the AGET-ATRP system is higher than those obtained from the normal ATRP and SR\&NI ATRP. This is because $\mathrm{CuBr}_{2}$ is more stable than its lower oxidation state analogue $(\mathrm{CuBr})$ that was used in the normal ATRP system. In the case of AGET-ATRP, the reduction of $\mathrm{CuBr}_{2}$ with $\mathrm{Sn}(\mathrm{EH})_{2}$ leads to a shift toward a dormant species. In this system, homo-polymerisation of the styrene and CMS is less likely to occur due to the fact that there is no radical initiator in this system. This is not the case for the SR\&NI-ATRP system where the decomposition of AIBN might induce homo-polymerisation of the monomers, leading to the lower rate of polymerisation. Similar results 


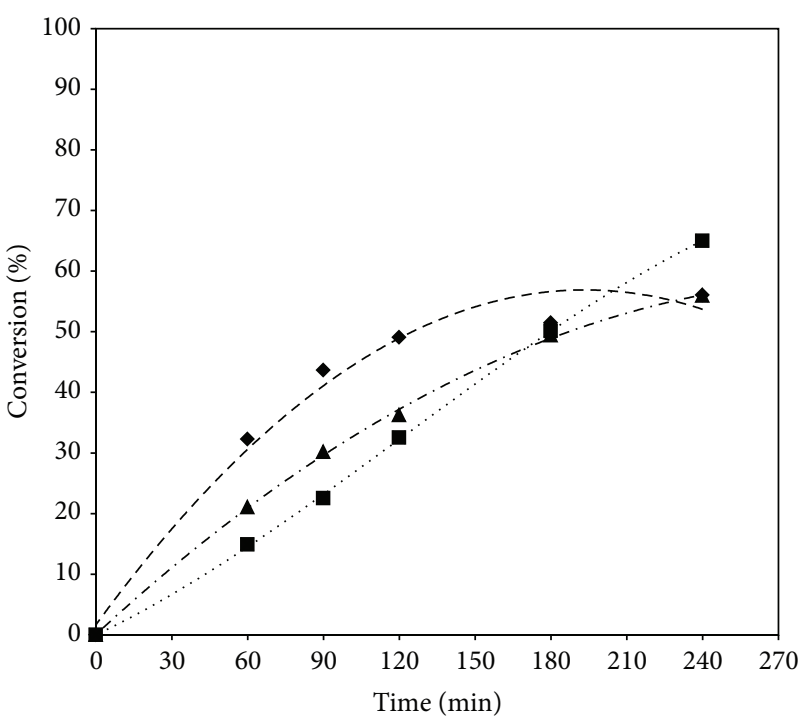

A Normal ATRP $[\mathrm{M}]:[\mathrm{P} 3 \mathrm{HT}-\mathrm{MI}]=300: 1$

- AGET ATRP $[\mathrm{M}]:[\mathrm{P} 3 \mathrm{HT}-\mathrm{MI}]=300: 1$

- SR\&NI ATRP $[\mathrm{M}]$ : [P3HT-MI $]=300: 1$

FIGURE 10: Relationships between monomer conversion and reaction time during polymerisations of styrene and chloromethylstyrene via different ATRP systems.

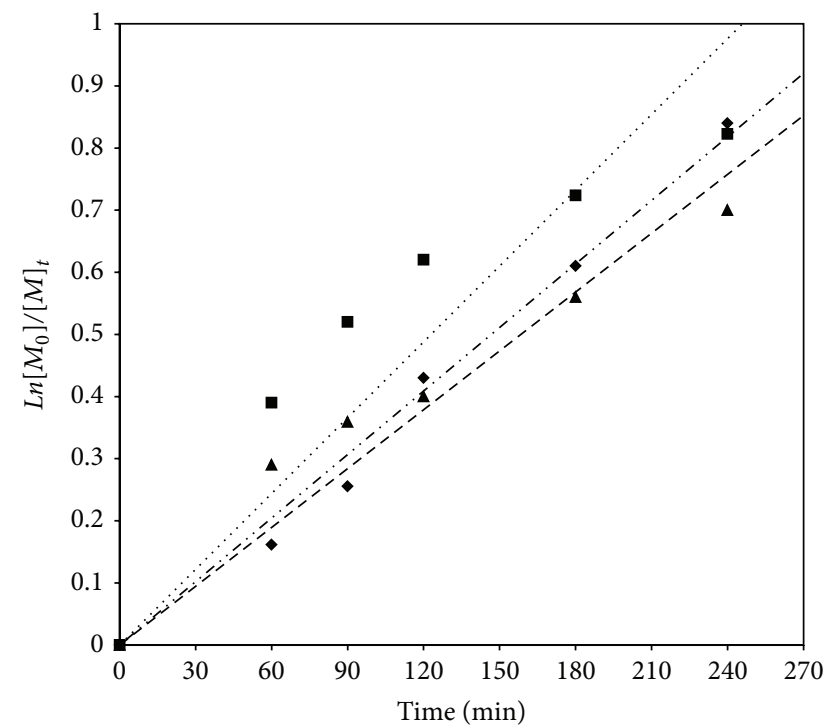

\ Normal ATRP $[\mathrm{M}]:[\mathrm{P} 3 \mathrm{HT}-\mathrm{MI}]=300: 1$

- AGET ATRP $[\mathrm{M}]:[\mathrm{P} 3 \mathrm{HT}-\mathrm{MI}]=300: 1$

- SR\&NI ATRP $[\mathrm{M}]:[$ P3HT-MI $]=300: 1$

FigURE 11: Kinetic plots of $\operatorname{Ln}\left[M_{0}\right] /[M]$ versus time for polymerisation of styrene and CMS via different ATRP systems, using the P3HT macroinitator (monomers/macroinitiator mole ratio $=300: 1$ ).

were observed by Lacroix-Desmazes et al. [23] in a study on poly(chloromethylstyrene-b-styrene) block copolymers.

Kinetic plots of $L_{n}\left[M_{0}\right] /[M]$ versus time for the polymerisation of styrene and CMS via different ATRP systems are illustrated in Figure 11. The three types of ATRP systems led to the first order kinetics with respect to the monomers.

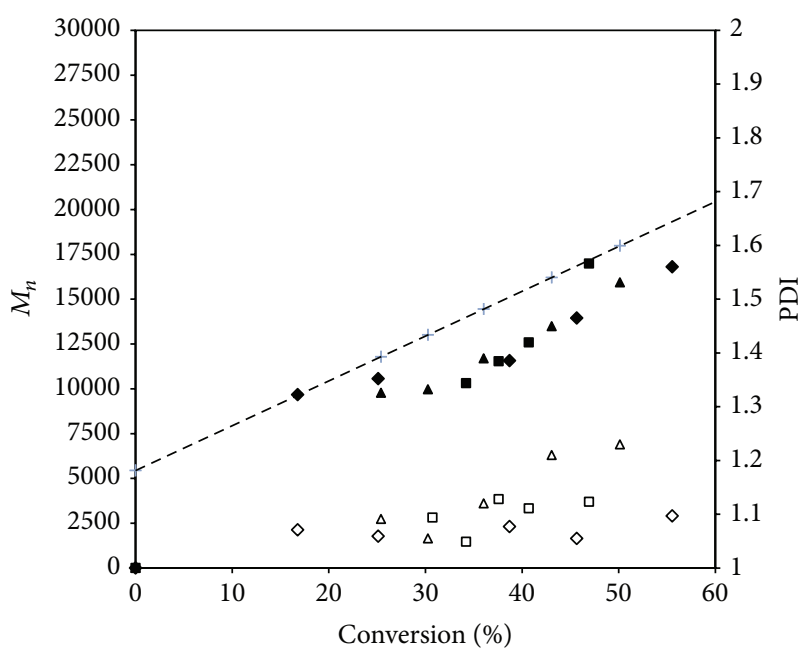

\ Normal ATRP $[\mathrm{M}]:[$ P3HT-MI $]=300: 1$

- AGET ATRP $[\mathrm{M}]:[$ P3HT-MI $]=300: 1$

- SR\&NI ATRP $[\mathrm{M}]:[$ P3HT-MI $]=300: 1$

$+M_{n}($ th) $300: 1$

$\triangle$ (PDI) normal ATRP $[\mathrm{M}]:[\mathrm{P} 3 \mathrm{HT}-\mathrm{MI}]=300: 1$

$\square$ (PDI) AGET ATRP $[\mathrm{M}]:[$ P3HT-MI $]=300: 1$

$\diamond(\mathrm{PDI})$ SR\&NI ATRP $[\mathrm{M}]:[\mathrm{P} 3 \mathrm{HT}-\mathrm{MI}]=300: 1$

FIgURE 12: Dependence of molecular weight and polydispersity index on monomer conversion for the polymerisation of styrene and CMS via different ATRP systems, using the P3HT macroinitator ( monomers/macroinitiator mole ratio $=300 / 1)$.

This behaviour is similar to those behaviours reported in the literature for the homopolymerisation of styrene via ATRP $[12,13]$. In this study, we found that the polymerisation rates among the three ATRP systems are slightly different. The rate constant $(k)$ for the AGET ATRP system is the highest $(4.1 \times$ $\left.10^{-3} \mathrm{~s}^{-1}\right)$, followed by that of SR\&NI ATRP $\left(3.4 \times 10^{-3} \mathrm{~s}^{-1}\right)$ and normal ATRP $\left(3.2 \times 10^{-3} \mathrm{~s}^{-1}\right)$, respectively.

Dependencies of the molecular weight and PDI on the monomer conversion of styrene and CMS from the three ATRP systems are also shown in Figure 12. PDI values of the products ranged from between 1.05 and 1.23. The values are considerably smaller than those generally obtained from a normal free radical polymerisation, as well as the other types of controlled radical polymerisation. Molecular weight values of the synthesised products, determined by GPC technique, are lower than the theoretical values, calculated by assuming a truly living polymerisation condition. This indicates that the ATRP polymerisation is not a truly living polymerisation and the reaction is not totally free from any chain transfer reactions. In addition, the chlorine atom of CMS has reactive functionality for ATRP and can act as an initiator and/or a chain transfer agent [24]. Therefore, chain transfer reactions to CMS and/or to the propagating polymer chains can occur. In theory, these side reactions could lead to the formation of various polymer structures, such as $\mathrm{P}(\mathrm{S}$-co-CMS) linear chains or $\mathrm{P}(\mathrm{S}-c o-\mathrm{CMS})$ grafted copolymers (structure No. (3) in Figure 13), in addition to more complex architecture, such as the hyper-grafted copolymer, based on P3HT- $b-\mathrm{P}(\mathrm{S}-$ co-CMS) backbone. The latter two by-products cannot be 


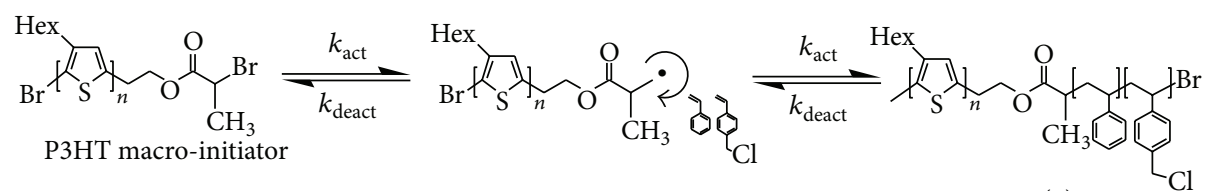

(1)

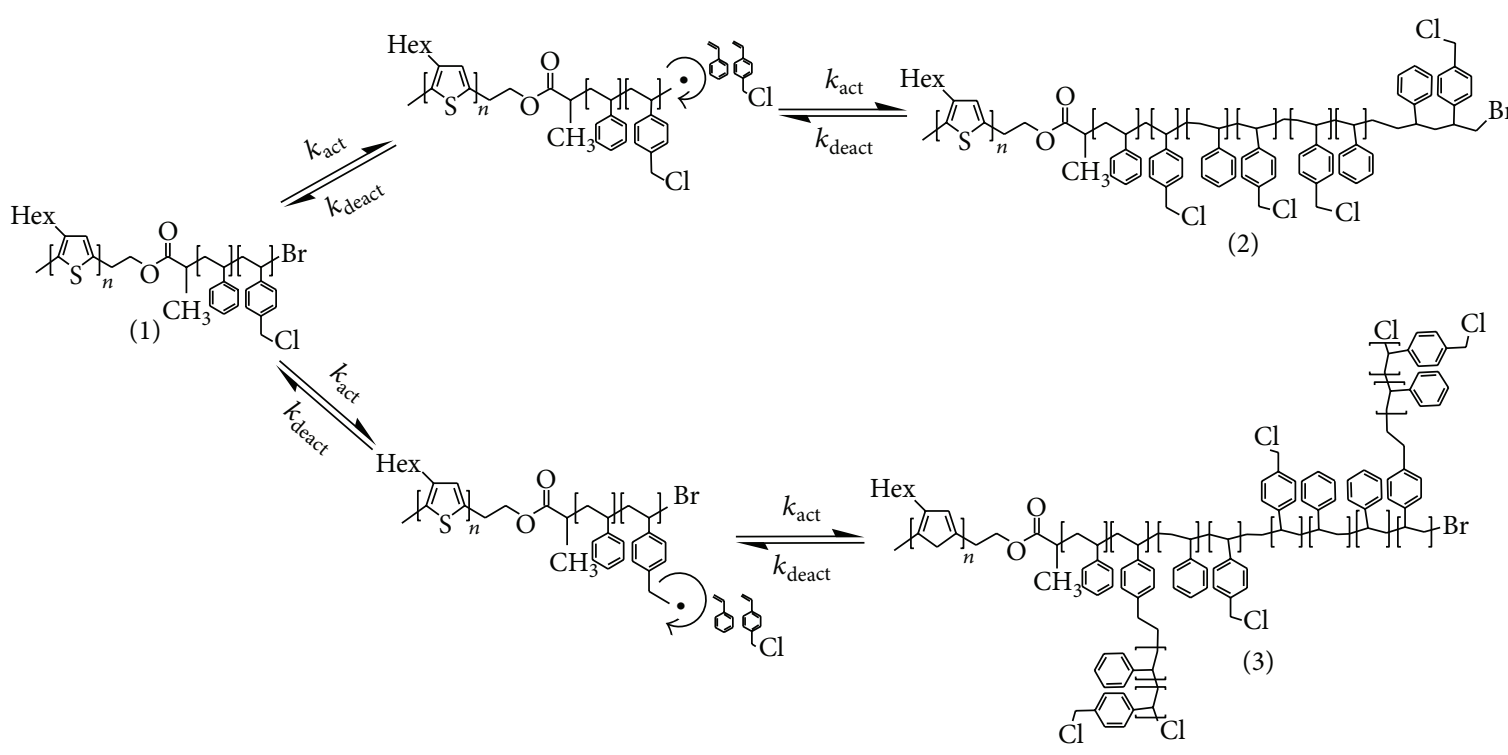

FIGURE 13: A schematic structure of a tentative byproduct attributed to chain transfer reactions occurring during the ATRP of styrene and CMS.

isolated from the main product by multiple extractions with several selective solvents. Due to the different molecular architectures and chain conformations, it might be possible that the presence of these remaining by-products contributed to a deviation of $M_{n}$ (determined from GPC technique) of the prepared product from its theoretical $M_{n}$ value.

Table 3 shows that by increasing the polymerisation time to 180 min or more, some differences in PDI values between the polymers obtained from the normal ATRP and those from the modified ATRP systems (AGET-ATRP and SR\&NI ATRP) were noted. In the latter cases, the PDI values of $\mathrm{P} 3 \mathrm{HT}-b-\mathrm{P}(\mathrm{S}-c o-\mathrm{CMS})$ ranged from $1.05-1.12$, which are slightly lower than the values from the normal ATRP (1.211.23). This indicates that the AGET-ATRP and SR\&NI ATRP systems are the better-controlled polymerisation systems.

Last but not least, morphology of the various block copolymers deserved a consideration. Figure 14 shows AFM micrographs of the P3HT- $b-\mathrm{P}$ (S-co-CMS), experiencing different types of ATRP methods. The micrographs obtained from a phase image tapping mode reveal the presence of two separated phases. The dark area represents the material with a relatively low modulus whereas the brighter area was more rigid. In relation to this study, these two phases corresponded to the P3HT block and the P(S-co-CMS) block in the copolymer, respectively. This was due to the fact that glass transition temperature of $\mathrm{P}(\mathrm{S}-\mathrm{co}-\mathrm{CMS})$ is about $81^{\circ} \mathrm{C}$ [24] which is greater than that of the P3HT macroinitiator $\left(67^{\circ} \mathrm{C}\right)$. From the above micrographs, a kind of dispersed particle morphology was noted, regardless of the types of ATRP systems used for the polymerization. The $\mathrm{P}(\mathrm{S}-\mathrm{co}-$ CMS) block was a minor phase being dispersed within the continuous P3HT matrix. This is in a good agreement with the results from Table 3 , showed that percentage composition of $\mathrm{P}(\mathrm{S}-\mathrm{co}-\mathrm{CMS})$ block in the copolymer is lower than that of the P3HT block. In other words, majority of the block copolymer molecule is P3HT. In this study, the effect of polymerization systems on morphology and phase size of the copolymer was not obvious. This was due to the fact that composition of the block copolymers was very similar (Table 3). Nevertheless, the above results indicate that the two blocks were incompatible and the phase separated morphology was induced.

Interestingly, after grafting fullerene groups onto the block copolymer molecules, using the ATRA technique, the AFM micrographs (Figure 15) in a topographic mode revealed that surface roughness of the block copolymers increased significantly. The above change could be attributed to the presence of $\mathrm{C}_{60}$. In relation to the bulk heterojunction polymer solar cell application, photovoltaic performance of the $\mathrm{BHJ}$ depends on many factors including the morphology of materials in the active layer. Generally speaking, the higher the surface roughness of the donor and acceptor materials, the greater the contact area between the active layer and the metal electrodes. Consequently, more efficient charge collection at the interface and the greater power conversion efficiency can be expected. 


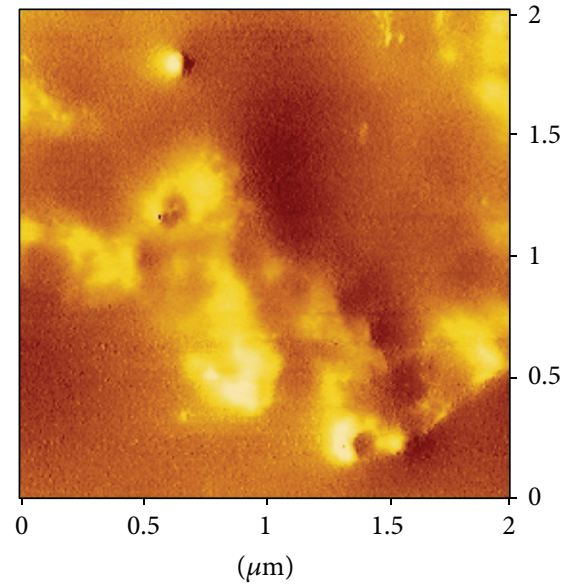

(a)

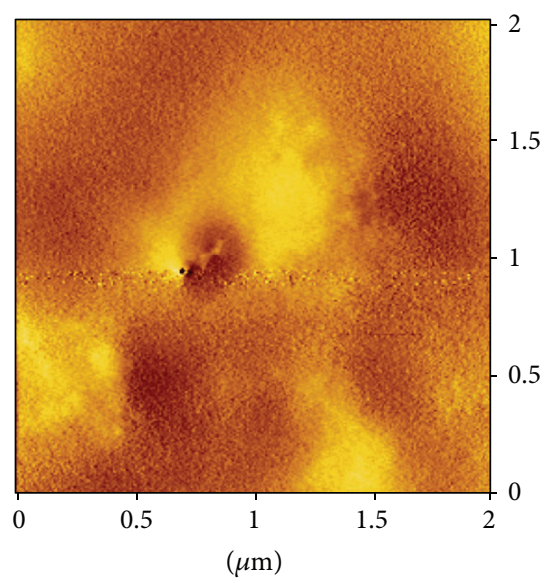

(c)

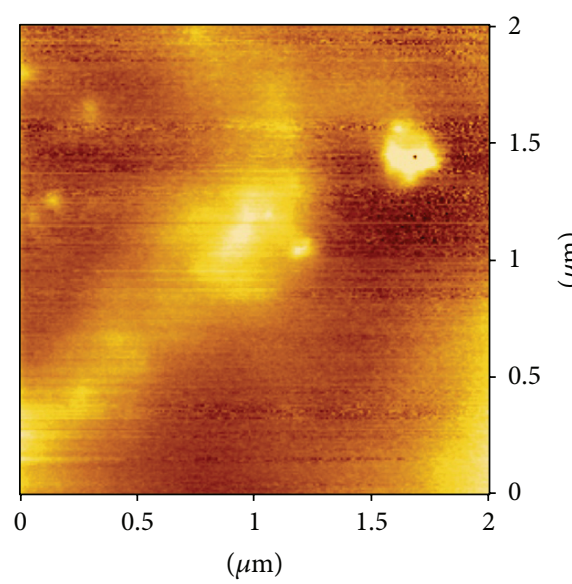

(e)

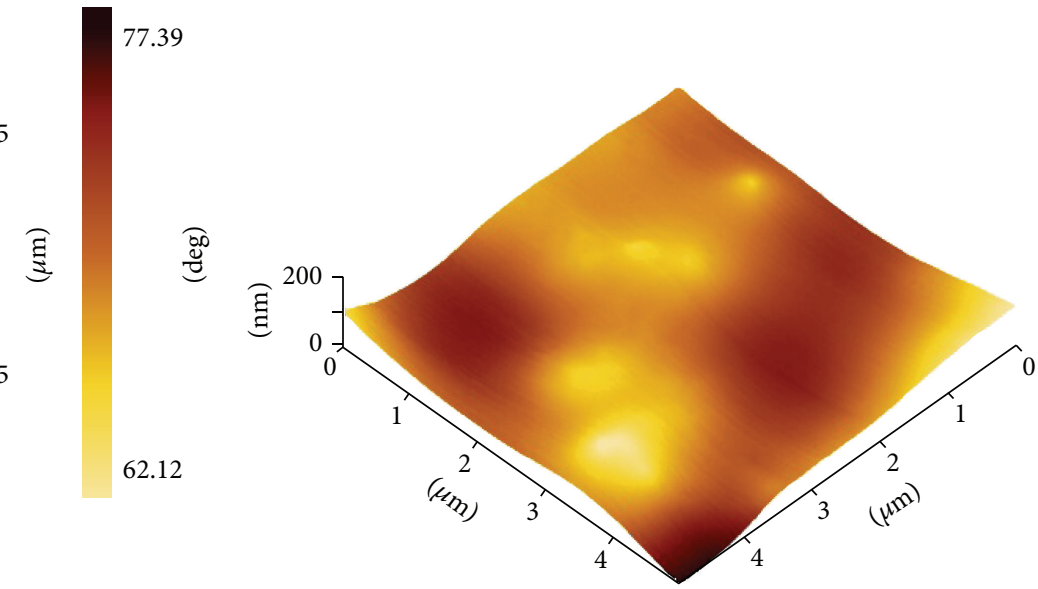

(b)

127.84

119.42

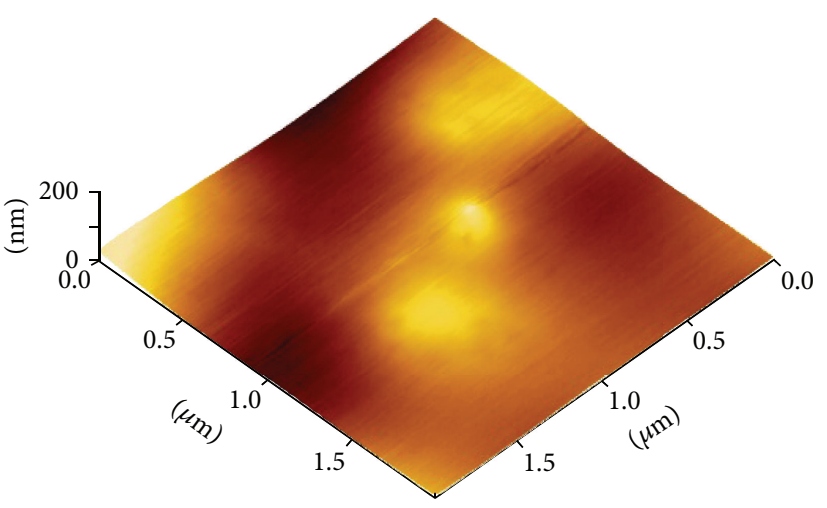

(d)

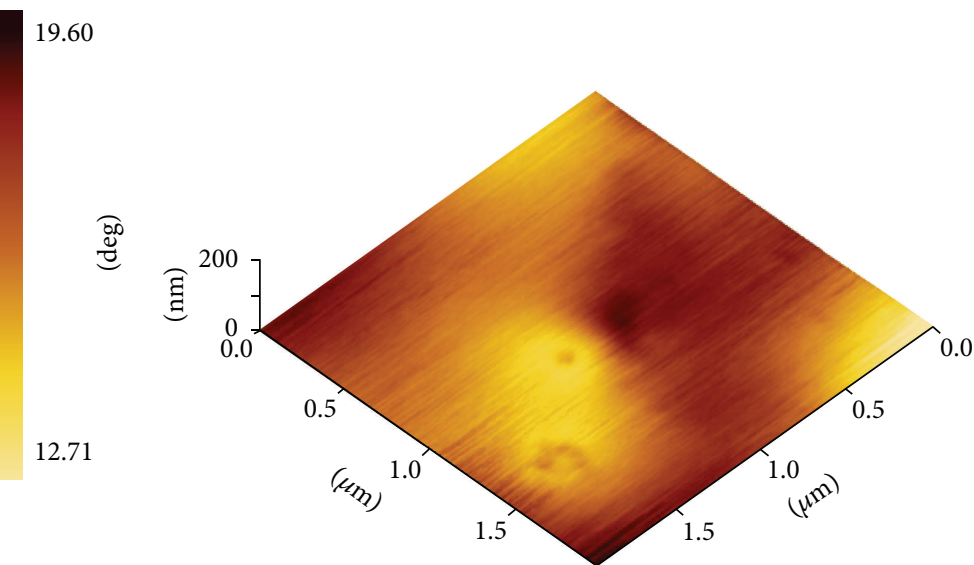

(f)

FIGURE 14: AFM micrographs of the P3HT- $b$-P(S-co-CMS) prepared by various ATRP systems; normal ATRP (top row), AGET-ATRP (middle row), and SR\&NI ATRP (bottom row). The micrographs were recorded in a phase image tapping mode (left column) and a topographic mode (right column).

\section{Conclusions}

P3HT- $b$-P(S-co-CMS) block copolymers were prepared via a chain extension of the P3HT macroinitator with styrene and CMS comonomers. Kinetics of three different ATRP systems, normal ATRP, AGET-ATRP, and SR\&NI ATRP, were studied. Results from the ${ }^{1} \mathrm{H}-\mathrm{NMR}$ analysis shows that the copolymer product containing the $\mathrm{P}(\mathrm{S}-\mathrm{co}$-CMS) block (with polystyrene repeating units as a major component) was obtained. The three types of ATRP systems led to the first order kinetics with 


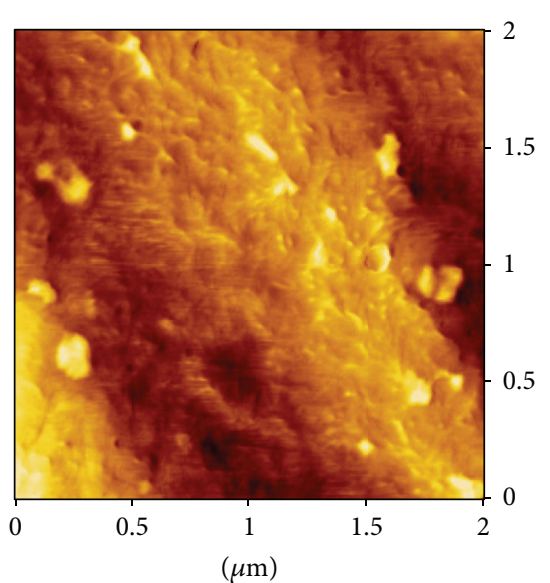

(a)

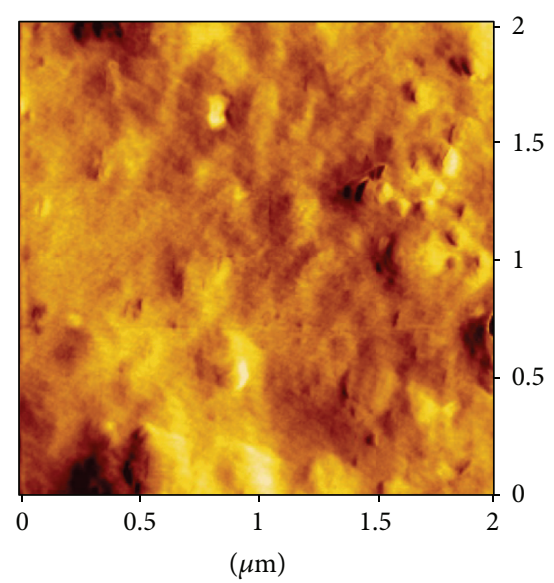

(c)

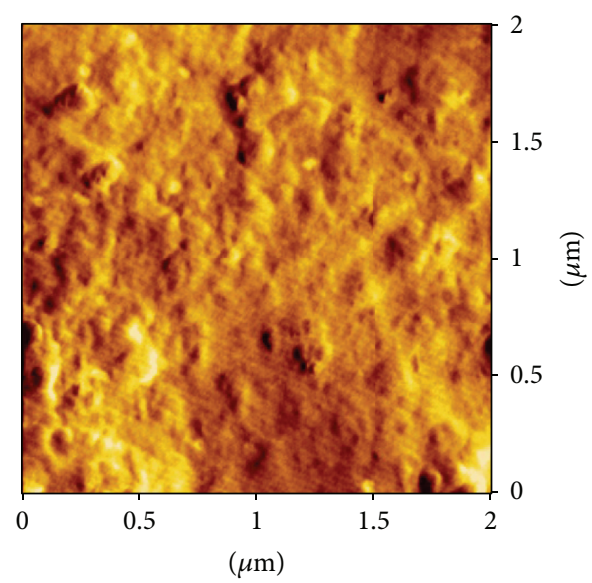

(e)
105.33

85.22

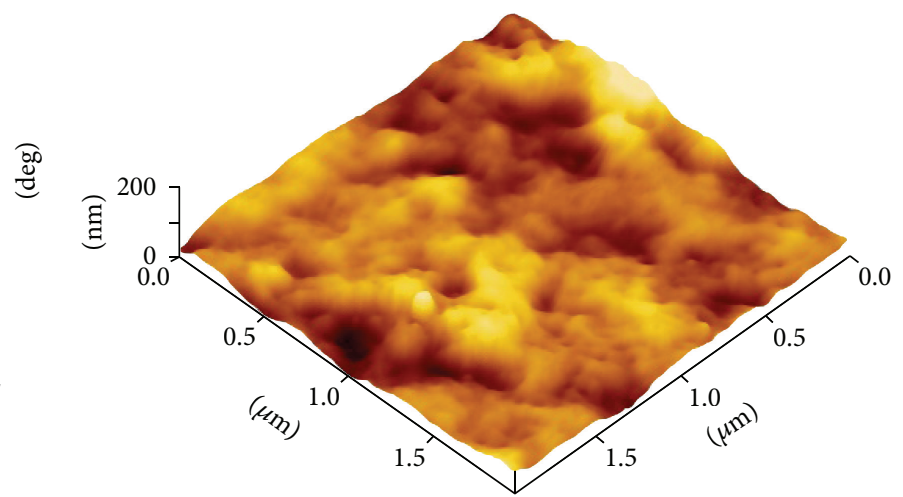

(b)

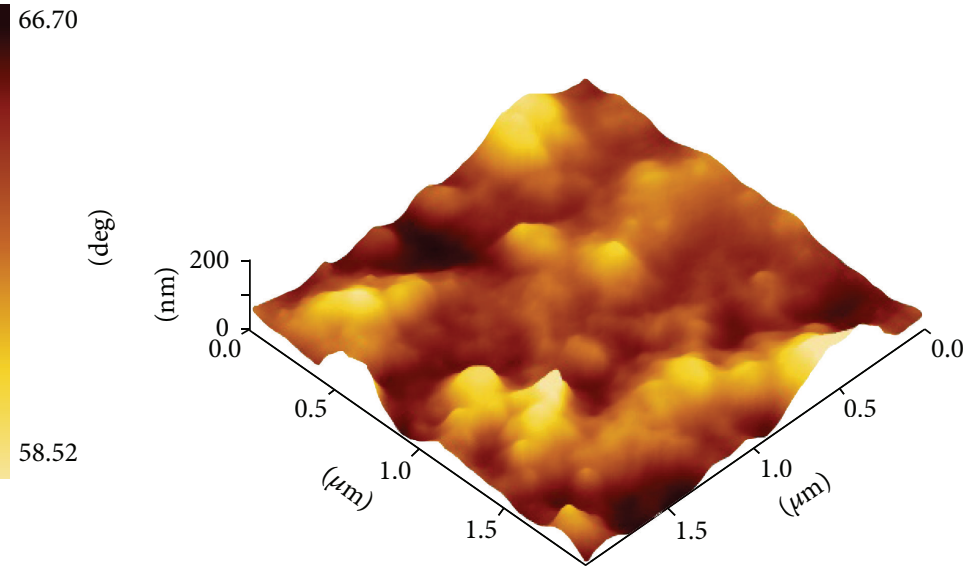

(d)

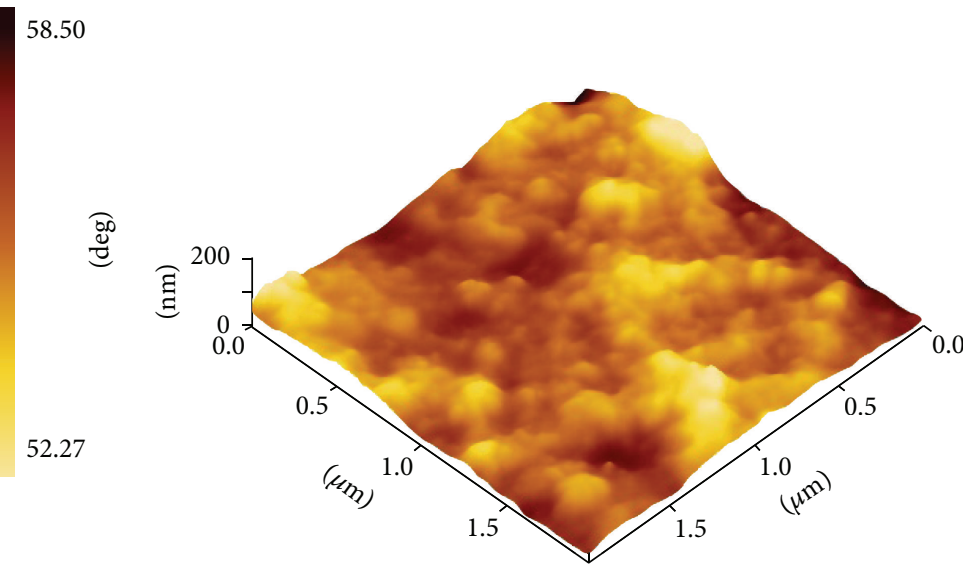

(f)

FIGURE 15: AFM micrographs of the donor-acceptor block copolymers (P3HT- $b$-PSFu) prepared by various ATRP systems; normal ATRP (top row), AGET-ATRP (middle row), and SR\&NI ATRP (bottom row). The micrographs were recorded in a phase image tapping mode (left column) and a topographic mode (right column).

respect to the monomers. The rate of polymerisation among the three different systems increased in the order of AGETATRP $>$ SR\&NI-ATRP $>$ normal ATRP. Polydispersity index values of the copolymer products obtained from the modified ATRP systems (AGET-ATRP and SR\&NI ATRP) ranged from
1.05-1.12, which are slightly lower than are the values from the normal ATRP system (1.21-1.23). The number average molecular weight $\left(M_{n}\right)$ of the block copolymer products is lower than that of the theoretical $M_{n}$ values, regardless of the polymerisation conditions. The discrepancies were 
discussed in light of the side reactions, including the chain transfer reaction from the propagating chain ends to the chlorine atoms along the $\mathrm{P}(\mathrm{CMS})$ repeating units of the copolymer chains. Results from AFM micrographs (phase image) indicated that the synthesized block copolymers are phase separated. Morphology of the block copolymers was also changed significantly after grafting with fullerene.

\section{Conflict of Interests}

There is no conflict of interests in this paper.

\section{Acknowledgments}

Mr. Nattawoot Rattanathamwat would like to thank the National Nanotechnology Center (NANOTEC) for the financial support during this doctoral study (Grant no. P10-10588). This work was also supported by the Nanotechnology Center (NANOTEC), NSTDA, Ministry of Science and Technology, Thailand, through its Center of Excellence Network programme.

\section{References}

[1] X. Fan, C. Cui, G. Fang et al., "Efficient polymer solar cells based on poly(3-hexylthiophene): indene- $\mathrm{C}_{70}$ bisadduct with a $\mathrm{MoO}_{3}$ buffer layer," Advanced Functional Materials, vol. 22, no. 3, pp. 585-590, 2012.

[2] B. C. Thompson and J. M. J. Fréchet, "Polymer-fullerene composite solar cells," Angewandte Chemie International Edition, vol. 47, no. 1, pp. 58-77, 2008.

[3] W. Cai, X. Gong, and Y. Cao, "Polymer solar cells: recent development and possible routes for improvement in the performance," Solar Energy Materials and Solar Cells, vol. 94, no. 2, pp. 114-127, 2010.

[4] S. E. Shaheen, D. S. Ginley, and G. E. Jabbour, "Organicbased photovoltaics: toward low-cost power generation," $M R S$ Bulletin, vol. 30, no. 1, pp. 10-15, 2005.

[5] E. Bundgaard and F. Krebs, "Low band gap polymers for organic photovoltaics," Solar Energy Materials and Solar Cells, vol. 91, no. 11, pp. 954-985, 2007.

[6] D. H. Wang, J. S. Moon, J. Seifter et al., "Sequential processing: control of nanomorphology in bulk heterojunction solar cells," Nano Letters, vol. 11, no. 8, pp. 3163-3168, 2011.

[7] Z. Sun, K. Xiao, J. K. Keum et al., "PS-b-P3HT copolymers as $\mathrm{P} 3 \mathrm{HT} / \mathrm{PCBM}$ interfacial compatibilizers for high efficiency photovoltaics," Advanced Materials, vol. 23, no. 46, pp. 55295535, 2011.

[8] J.-S. Wang and K. Matyjaszewski, “Controlled/'living' radical polymerization. atom transfer radical polymerization in the presence of transition-metal complexes," Journal of the American Chemical Society, vol. 117, no. 20, pp. 5614-5615, 1995.

[9] W. A. Braunecker and K. Matyjaszewski, "Controlled/living radical polymerization: features, developments, and perspectives," Progress in Polymer Science, vol. 32, no. 1, pp. 93-146, 2007.

[10] J. Chiefari and E. Rizzardo, "Control of free-radical polymerization by chain transfer methods," in Handbook of Radical Polymerization, K. Matyjaszewski and T. P. Davis, Eds., chapter 12, pp. 629-690, Wiley, 2003.
[11] M. Y. Khan, Z. Xue, D. He, S. K. Noh, and W. S. Lyoo, "Comparative study of a variety of ATRP systems with high oxidation state metal catalyst system," Polymer, vol. 51, no. 1, pp. 69-74, 2010.

[12] K. Matyjaszewski, T. E. Patten, and J. Xia, “Controlled/'living' radical polymerization. Kinetics of the homogeneous atom transfer radical polymerization of styrene," Journal of the American Chemical Society, vol. 119, no. 4, pp. 674-680, 1997.

[13] H. Arslan, Y. Kucuk, A. Mente, and M. H. Acar, "A kinetic study of atom transfer radical polymerization of styrene with bis(2-pyridyl)ethylenedimethanimine derivative ligands," Turkish Journal of Chemistry, vol. 37, pp. 824-831, 2013.

[14] M. Lazzari, O. Chiantore, R. Mendichi, and M. Arturo LópezQuintela, "Synthesis of polyacrylonitrile-block-polystyrene copolymers by atom transfer radical polymerization," Macromolecular Chemistry and Physics, vol. 206, no. 14, pp. 1382-1388, 2005.

[15] M. C. Iovu, M. Jeffries-El, E. E. Sheina, J. R. Cooper, and R. D. McCullough, "Regioregular poly(3-alkylthiophene) conducting block copolymers," Polymer, vol. 46, no. 19, pp. 8582-8586, 2005.

[16] N. Rattanathamwat, J. Wootthikanokkhan, N. Nimitsiriwat, C. Thanachayanont, U. Asawapirom, and A. Keawprajak, "Poly(3hexyl thiophene)-b-fullerene functionalized polystyrene copolymers (P3HT-b-PSFu) as compatibilizer in P3HT/PhenylC61-butyric acid methyl ester (PCBM) solar cells," International Journal of Polymeric Materials and Polymeric Biomaterials, vol. 63, no. 9, pp. 448-455, 2014.

[17] X. Chen, B. Gholamkhass, X. Han, G. Vamvounis, and S. Holdcroft, "Polythiophene-graft-styrene and polythiophenegraft-(styrene-graft-C 60) copolymers," Macromolecular Rapid Communications, vol. 28, no. 17, pp. 1792-1797, 2007.

[18] N. Seeponkai, N. Keaitsirisart, J. Wootthikanokkhan, C. Thanachayanont, and S. Chuangchote, "Fullerene functionalized polystyrene: synthesis, characterizations, and application in bulk heterojunction polymer solar cells," International Journal of Polymeric Materials and Polymeric Biomaterials, vol. 63, no. 1, pp. 33-40, 2014.

[19] G. Odian, "Radical chain polymerization," in Principles of Polymerization, G. Odian, Ed., chapter 3, pp. 198-349, John Wiley \& Sons, New York, NY, USA, 2004.

[20] J. D. Peterson, S. Vyazovkin, and C. A. K. Wight, "Kinetics of the thermal and thermo-oxidative degradation of polystyrene, polyethylene and poly(propylene)," Macromolecular Chemistry and Physics, vol. 202, no. 6, pp. 775-784, 2001.

[21] C. Kavakli, N. Özvatan, S. A. Tuncel, and B. Salih, "1,4,8,11Tetraazacyclotetradecane bound to poly( $p$-chloromethylstyrene-ethylene glycol dimethacrylate) microbeads for selective gold uptake," Analytica Chimica Acta, vol. 464, no. 2, pp. 313$322,2002$.

[22] B. K. Kuila, K. Park, and L. Dai, "Soluble P3HT-grafted carbon nanotubes: synthesis and photovoltaic application," Macromolecules, vol. 43, no. 16, pp. 6699-6705, 2010.

[23] P. Lacroix-Desmazes, T. Delair, C. Pichot, and B. Boutevin, "Synthesis of poly(chloromethylstyrene-b-styrene) block copolymers by controlled free-radical polymerization," Journal of Polymer Science Part A: Polymer Chemistry, vol. 38, no. 21, pp. 3845-3854, 2000.

[24] H.-J. Paik, S. G. Gaynor, and K. Matyjaszewski, "Synthesis and characterization of graft copolymers of poly(vinyl chloride) with styrene and (meth)acrylates by atom transfer radical polymerization," Macromolecular Rapid Communications, vol. 19, no. 1, pp. 47-52, 1998. 

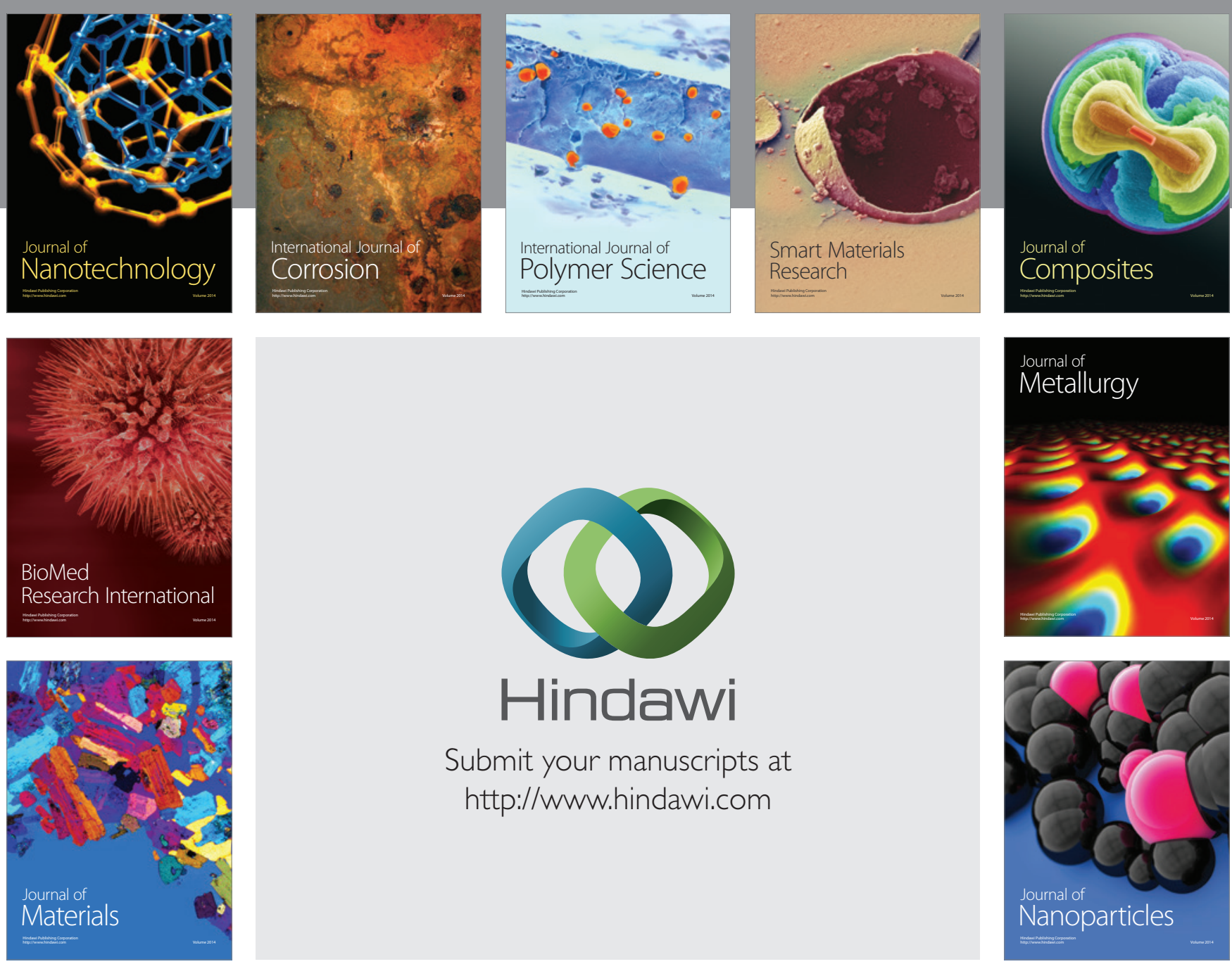

Submit your manuscripts at http://www.hindawi.com
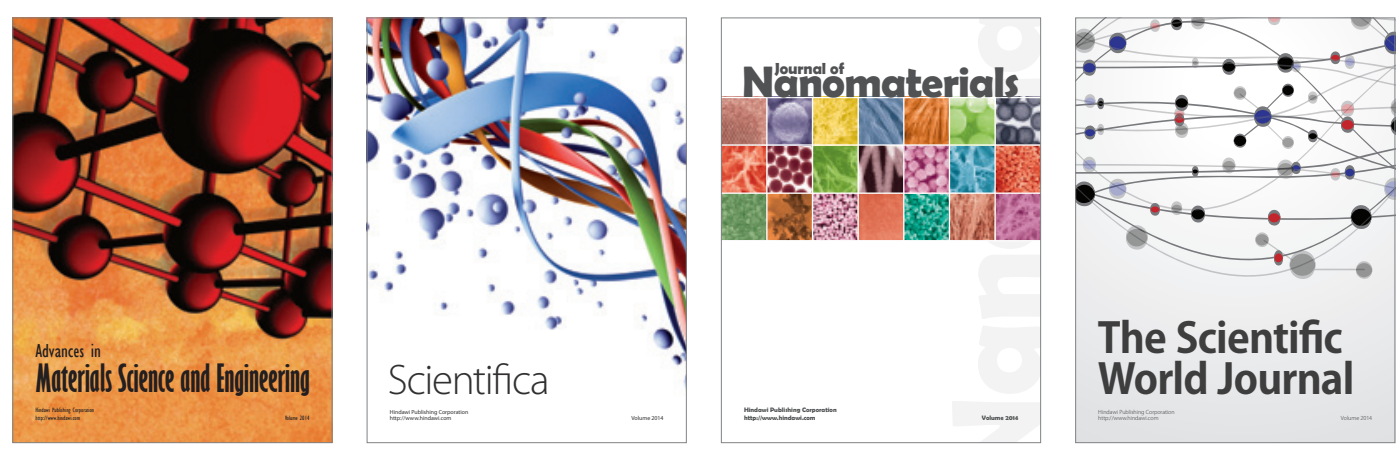

\section{The Scientific World Journal}
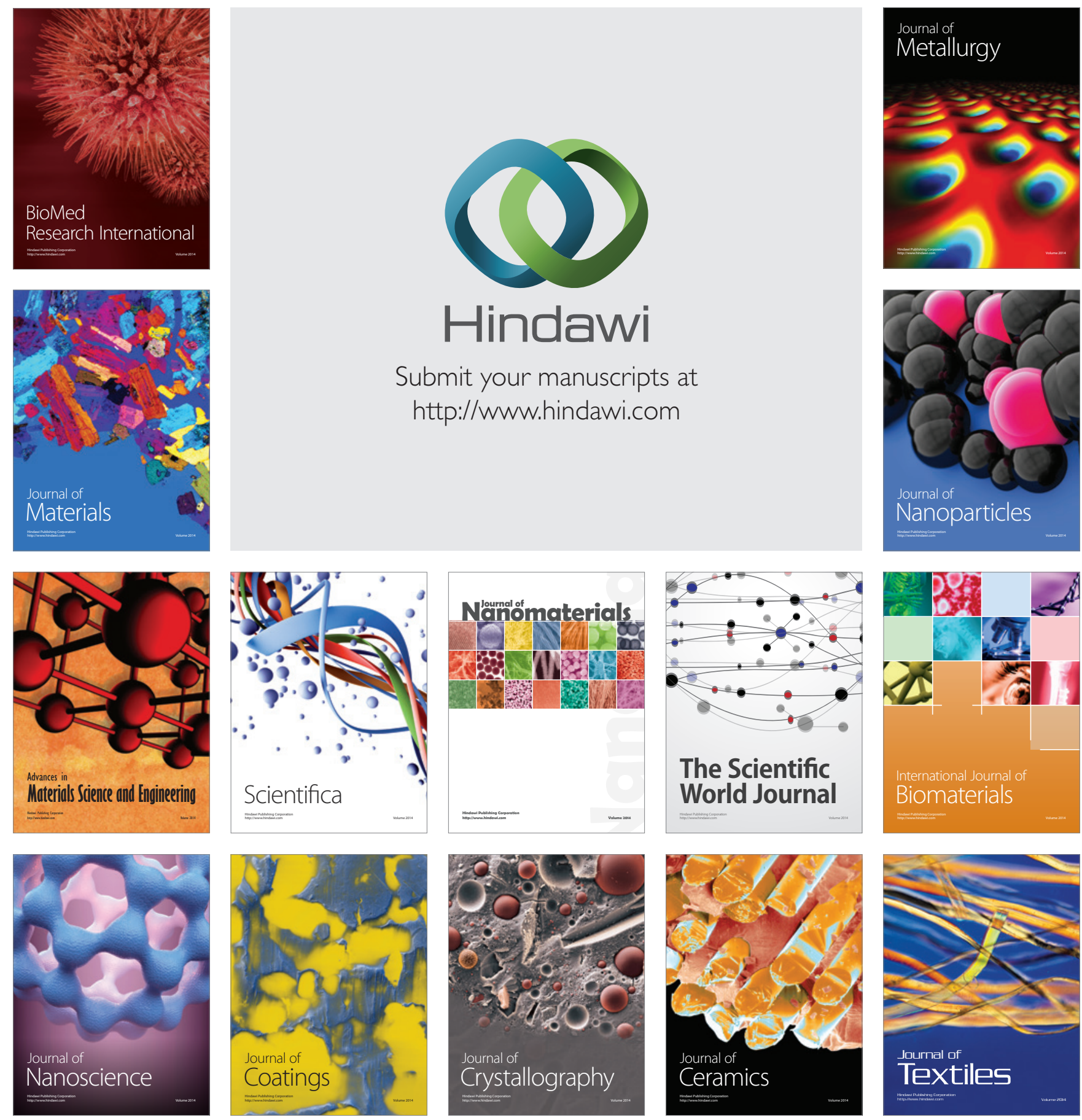